\title{
Weldability of duplex stainless steel
}

\author{
A. Pramanik*, G. Littlefair ${ }^{1}$, A.K. Basak ${ }^{2}$ \\ *Phone: 61892667981 \\ *Fax: 61892662681 \\ *Email: alokesh.pramanik@curtin.edu.au; akprama@yahoo.com \\ *Department of Mechanical Engineering, Curtin University, Bentley, WA 6102, Australia \\ ${ }^{1}$ School of Engineering, Deakin University, Waurn Ponds, VIC, Australia \\ ${ }^{2}$ Center for Advanced Microscopy, Australian National University, Canberra ACT 0200 \\ Australia
}

\begin{abstract}
The duplex stainless steels (DSS) have many advantages due to unique structural combination of ferrite and austenite grains. The structural change of these materials is very complex during welding and it deteriorates the functional properties. This research investigates different welding processes, such as laser beam, resistance, TIG, friction stir, submerged arc, and plasma arc weldings considering the research available in the literature. The welding mechanism, change of material structure and control parameters have been analysed for every welding process. This analysis clearly shows that duplex stainless steel melts in all most all welding processes but the thermal cycle and maximum heat input are different. This difference affects the resulting structure and functional properties of weld significantly.
\end{abstract}

Key words: welding, weldabilty, ferrite, austenite, stainless, steels, structures, temperature, duplex. 


\section{Introduction}

DSS are made of austenite and ferrite microstructures [1]. The structure of duplex stainless steels has almost equal parts of these phases after proper heat treatment [2]. There are several advantages of this steel grade compare to general stainless steels. The lesser phase of this material should not be less than $30 \%$ by volume to maintain required properties of this material. DSS are stronger than their constituents [3, 4]. Those also have twice of the yield strengths compare to that of austenitic grades while holding worthy ductility and toughness [5]. The thermal expansion coefficient and the heat transfer properties of the DSS are intermediate between its constituent. The cost of duplex stainless is less sensitive to nickel price as it contains smaller amount of nickel compare to that of common austenitic stainless steel [6].

DSS are quite old materials and available since 1930s. The first-generation DSS, such as type 329 have decent localized resistance to corrosion because of the high contents of chromium and molybdenum. Alloying with nitrogen has inspired the manufacture of many DSS, most of which are marketed as trademarked produces. Among those, 2205 alloy is extensively available and the broadly used second-generation DSS [6]. Many of the second-generation DSS are obtainable as castings along with wrought produces which have improved the variety of application of these alloys. Alloy 2205 is applied to handle the problematic cracking of tanks and piping of hot water system due to stress corrosion [3]. Duplex alloy grade 2205 has been used in chemical carrier where the damage due to thermal shock may arise into austenitic stainless-steel in harsh and corrosive environments. Wider application of DSS is noted in oil and gas industries due to the favourable arrangement of strength and corrosion resistance $[6,7]$.

In most of the applications, the duplex stainless steels need to undergo welding process while joining two parts together. The heating cycle in welding process significantly affects the properties of these materials around the welded joints. During heating (around $1350{ }^{\circ} \mathrm{C}$ ) and holding period, most of the austenite phases in the duplex structure dissolve into the ferrite matrix, and ferrite grains grow coarse. During the cooling stage in the temperature range of 1350 to $800{ }^{\circ} \mathrm{C}$, austenite re-precipitates around ferrite grain boundaries. The final structure depends on the parameters of thermal cycles such as holding time, peak temperature, and the cooling rate from 1350 to $800{ }^{\circ} \mathrm{C}$. Among these, the rate of cooling from 1350 to $800{ }^{\circ} \mathrm{C}$ is 
significant. Usually, high cooling rate result in exceptionally coarse ferrite grains, which is detrimental to both mechanical and corrosion properties [3, 8]. However, conversion of sufficient amount of austenite and preclusion of intermetallic compounds are necessary to maintain the quality. Generally, greater than $75 \%$ (approximately) of ferrite content is undesirable for most of the uses [6]. Extreme exposure of DSS in the range of $700-955^{\circ} \mathrm{C}$ has a tendency to generate intermetallic compounds of iron, molybdenum and chromium [3]. These compounds are disadvantageous to toughness and resistance of corrosion [9]. The speed of forming these compounds is extreme at 815 to $870^{\circ} \mathrm{C}$. The understanding of the factors that affect the weldability of duplex stainless steel is critical for practical application of these materials as the welding process is widely used to process those $[5,10,11]$. It is already mentioned that the balance of ferrite-austenite remarkably affect both the corrosion and mechanical behaviours of DSS [2]. Nearly equal proportions of austenite and ferrite phases provide optimum characteristics of this material. The phase balance in base metals is achieved by an appropriate combination of composition and solution heat treatment. However, control of the ferrite/austenite balance in welds is not as straightforward as in the base metals [12]. The main goal in welding of DSS is to have outstanding corrosion and mechanical characteristics in fusion and heat affected zones for different applications [10]. DSS generally demonstration decent weldability [1]. However, the heating and cooling cycles during welding degrade the favourable structure of these materials. Generally, the islands of austenite in ferrite are transverse as well as parallel to the rolling path in the duplex stainless steels. However, intergranular and intragranular austenite grains as well as the coarse ferrite grains are produced during fusion welding which change that microstructure of welding zones [13-15]. It has been demonstrated that microstructures of weld and heat affected zones depends on the cooling rate from peak temperature [16]. Thus, proper regulation of the weld metal constituents and welding parameters are required during the process [15, 17, 18]. Consequently, it is expected that the ferrite/austenite balance in fusion zone is affected by type of welding process $[10,19]$.

The above discussion clearly shows the importance of the duplex stainless steels and associated complexities to retain properties of these materials after welding. Researchers have applied different welding methods and analysed the change of microstructures. The change of microstructure is a complex process and depends on the welding parameters [20-22]. Thus, the welding of this material is still challenging but the available data is not well organised, not linked properly and difficult to follow. Considering the above facts this paper 
systematically analyses the different welding mechanism and subsequent changes in microstructure based on the research available in the literature. This will be beneficial for better understanding and compare different welding methods of duplex stain less steal in easier way and help industry people to optimize welding process and minimize the cost of duplex welding.

\section{Laser beam welding}

In laser beam welding, high intensity heat source is used which causes high cooling rate after welding process [23]. This changes the behaviours and configuration of DSS [24-26]. At the time of the solid-state cooling to ambient temperature, the $\gamma$-austenite phases in the duplex stainless steel nucleate at $\delta$-ferrite grain boundaries. The volume of austenite at room temperature depends on the thermal history of welding process $[27,28]$. Thus it is critical to control the cooling rate which generally depends on the material's thermal properties and heat input. The rate of cooling can only be controlled by heat input when the material properties do not change. The heat input during laser welding generally depends on speed, absorption, and power of the laser. Among these, controlling the absorption is very difficult as it depends on the beam wavelength and workpiece materials. Thus, the heat input can be regulated by laser power or welding speed [29, 30]. The increased rate of cooling and higher initial temperature increases ferrite phase in the welded material [27, 29]. Pekkarinen et al., [29] noted 15 percentage increase of ratio of ferrite to austenite by adjusting the heat of laser. Decrease of heat input and increase of speed can introduce a low cooling rate in a preferable thermal cycle. Thus, a favourable austenite-ferrite ratio can be achieved by regulating the laser heat and the rate of cooling instead of using a filler. The composition of steel defines the limits of welding parameters that control the ferrite-austenite ratio. The 2205 grade duplex steel generates approximately ten percentage higher ferrite count than that in 2101 grade under the same heat input [29]. 2101 grade duplex steel has lower nickel (1.6\%) content compare to that $(5.7 \%)$ of 2205 grade duplex steel. Filler metals contain the elements to stabilizing austenite are generally used to recompense this effect. In addition, nitrogen enhanced shielding and backing gases are also believed to reduce the austenite formation effectively [31, 32].

According to Mourad et al., [10] the optimal parameters for butt welding of 2205 duplex stainless steel by carbon dioxide type laser are power $8 \mathrm{~kW}$, distance of defocusing $0.0 \mathrm{~mm}$, speed $0.5 \mathrm{~m} / \mathrm{min}$ and rate of gas flow $20 \mathrm{l} / \mathrm{min}$. The macrographs of the top and cross- 
sectional views of the laser beam welded joint produced by the above-mentioned parameters are shown in Fig. 1. In this case, the fusion zone is slightly tapered (Fig. 1b) which has a relatively high depth to width ratio (1.4). It is noteworthy that a symmetrical fusion zone was produced about the axis of the laser beam and the fusion zone interface is smooth with no inflections (Fig. 1). Higher welding speed $(\geq 6 \mathrm{~m} / \mathrm{min})$ or a lower laser power $(\leq 4 \mathrm{~kW})$ produce incomplete weld penetration, i.e., a lower ratio of depth to width and unsatisfactory weld profile. The Fig. 2 demonstrates the welded structure of the 2205 DSS base metal. The ferrite and austenite phases are designated as $\mathrm{F}$ and $\mathrm{A}$ respectively in the micrographs. The microstructure of duplex consists of almost equal portion of ferrite and austenite phases [10].
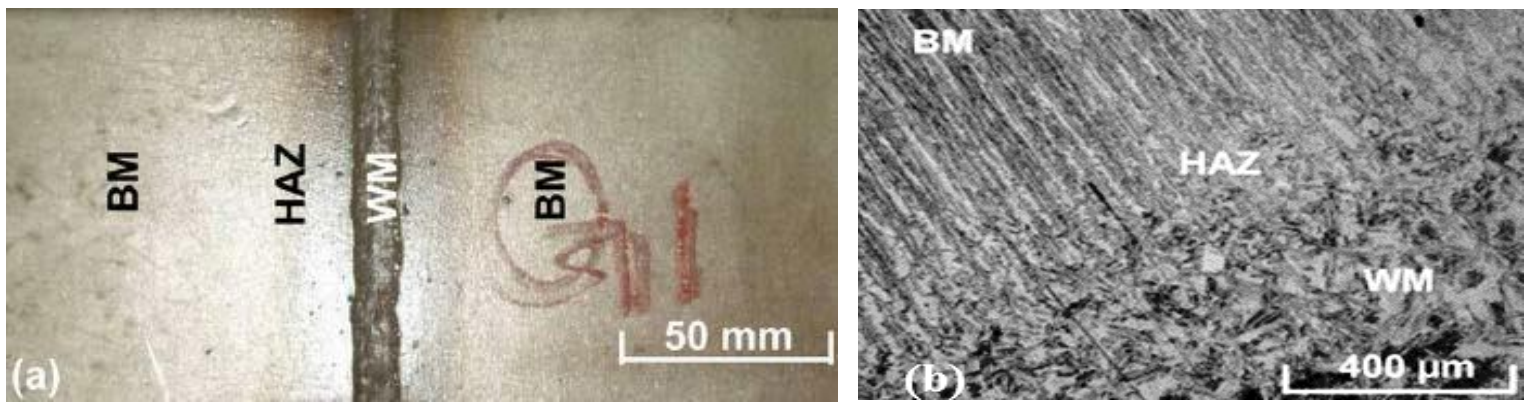

Fig. 1 Macrographs of (a) the top and (b) cross-sectional views of the laser beam welded joint showing the different welding regions, where BM-base metal, WM-weld melt, HAZ -heat affected zone [10].

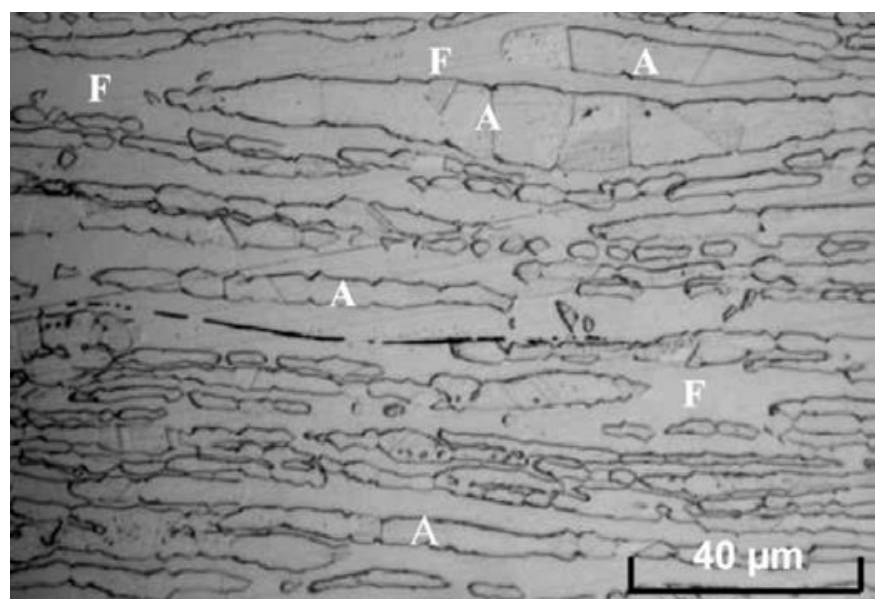

Fig. 2 Structure of 2205 DDS after welding at optimum conditions [10].

Capello et al., [27] carried out welding tests by making beads on plates. The welding was performed in $6 \mathrm{~kW}$ transverse flow $\mathrm{CO}_{2}$ laser which generated a quality parameter of $M^{2} \approx 8$. A $200 \mathrm{~mm}$ parabolic mirror was used to focus the beam. $\mathrm{N}_{2}$ flowed $30 \mathrm{l} / \mathrm{min}$ as shielding gas at 10 bar and $60^{\circ}$ from the welded side. To counterbalance amount of different phases in the 
welded joint, heat treatment of welded surface was done by the same laser. Fig. 3 displays that the as weld structure contains elongated primary ferrite which was orientated according to the direction of heat flux. Austenite was noted in small amount which precipitated as finer state primarily from the grain boundaries of ferrite.
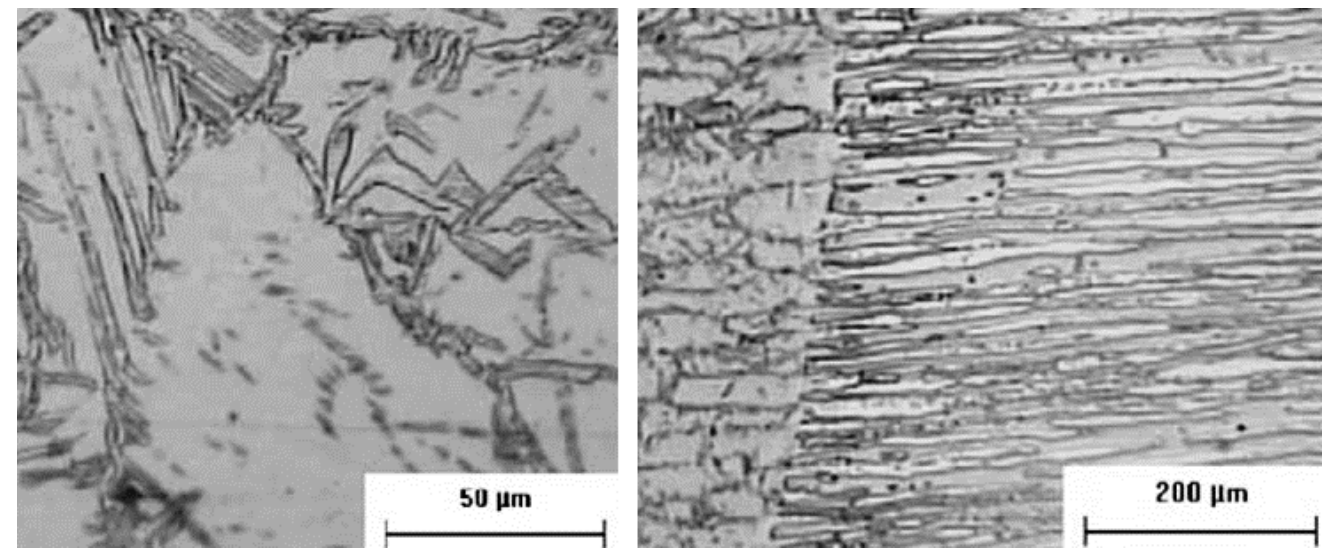

Fig. 3 From left (a) weld metal zone microstructure (b) microstructure at fusion line [27].

The range of laser affected region depends on the distance of the location from the weld top [33]. Figure 4 shows the heat treated weld structures at different distance from the top surface. This sample was treated at laser power $1.20 \mathrm{kw}$, scan speed $1 \mathrm{~mm} / \mathrm{s}$ and focus height $65 \mathrm{~mm}$. The heat treated weld metal structure contains higher quantity of austenite which was formed at intragranular locations and grain periphery. The figure also shows that the ferrite phase decomposed partially due to the growth of the austenite phase from the initial coarse grain peripheries and formation and/or development of slight precipitates in ferrite grains [27].

Chen et al., [3] studied effect of cooling rate during fusion welding of duplex stainless steel 2304 where the peak temperature was $1350{ }^{\circ} \mathrm{C}$ which was held for $2 \mathrm{~s}$ and then cooled down to $800{ }^{\circ} \mathrm{C}$ at different rates, such s $10,20,30,50$ and $100{ }^{\circ} \mathrm{C} / \mathrm{s}$. The compositions of $\mathrm{HAZ}$ at different cooling rates are presented in Table 1. The results show that the content of austenite increases progressively with the reduction $\left(100-10^{\circ} \mathrm{C} / \mathrm{s}\right)$ of the cooling rate. For all the cases, austenite phase was surrounded by ferrite phase and, austenite grains become longer and broader with the decrease of the rate of cooling. The formation of austenite is organized by a para-balanced conversion mechanism [34] where the reduction of the cooling rate yields the dispersion of austenite balancing elements $(\mathrm{N}$ and $\mathrm{Ni}$ ) and confirms the conversion of ferrite to austenite. 

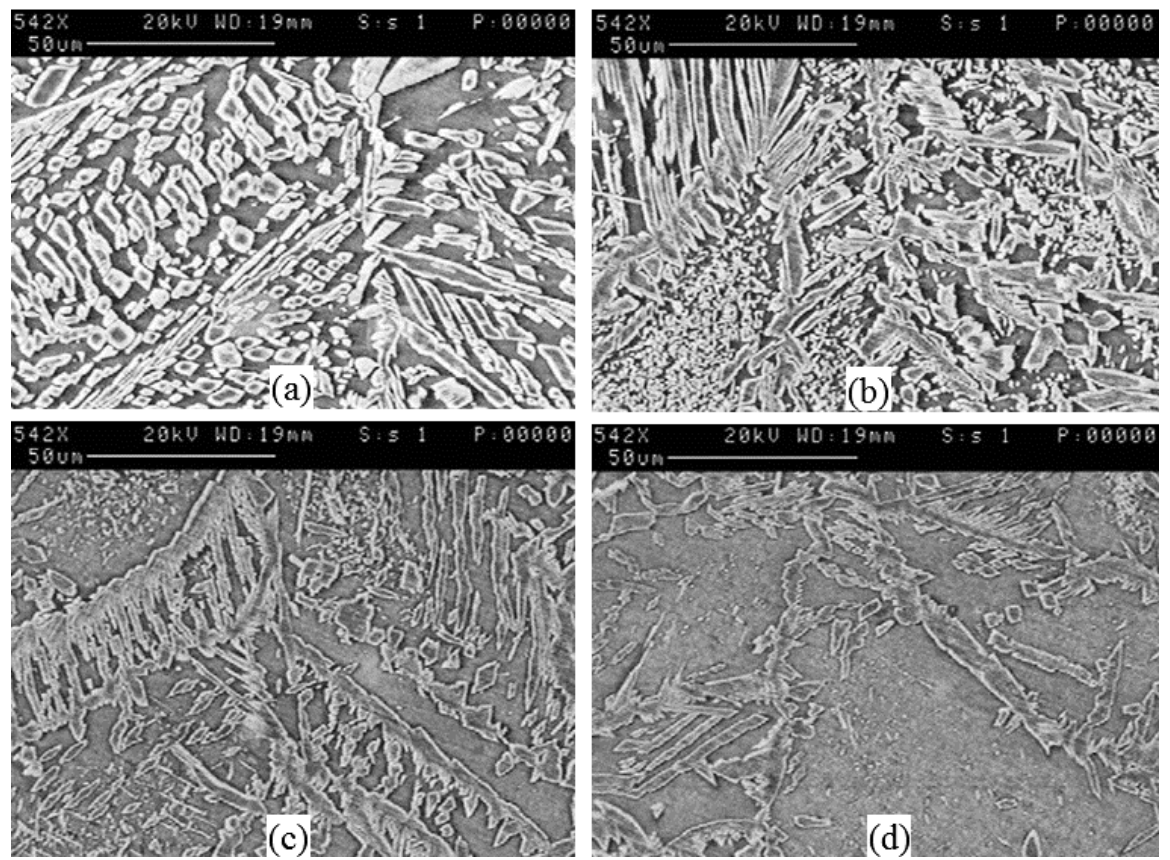

Fig. 4 Weld structure after heat treatment (a) near the top surface, and (b) 1.1, (c) 2.1 and (d) $2.7 \mathrm{~mm}$ below the top [27].

Table 1 Amount of different phases of 2304 DSS at various cooling rates

\begin{tabular}{|c|c|c|}
\hline Cooling rate $\left({ }^{\circ} \mathrm{C} / \mathrm{s}\right)$ & Ferrite $(\%)$ & Austenite (\%) \\
\hline 100 & 72.2 & 27.8 \\
\hline 50 & 71.5 & 28.5 \\
\hline 30 & 68.4 & 31.6 \\
\hline 20 & 66.1 & 33.9 \\
\hline 10 & 64.3 & 35.7 \\
\hline
\end{tabular}

\section{Resistance welding}

The resistance welding process does not need filler metal and no cast nugget is formed. It merges the entire adjoining surfaces simultaneously by the heat generated by resisting the flow of electricity between the two surfaces. In addition, the pressure is applied when heating is considerably finished [35-37]. Initially, the heating is produced by the irregular arc and restricted in the welding area. The weld mates are heated to the melting point and material is pressed out through the adjacent areas. When the material is flashed away a minor arc and the heating are continued until the whole surfaces reach the melting point. The heat is localized 
and very high due to flashing action. Thus, the metallurgical changes are obvious in the weld joint [38].

Kuroda and Shimada [38] obtained the temperature vs time graph during flash butt welding for super DSS (329J4L). The curves are given in Fig. 5. The heating was regulated and heated to $1373 \mathrm{~K}$ for 30,20 , and $10 \mathrm{sec}$ which varied the condition of contact between the adjoining samples. The temperature change during heating is known as zig-zag phenomenon in the curve, continued until the temperature starts to drop. The zig-zag phenomenon confirms the joining process. These zig-zag phenomena are hardly shown when the samples are heated without joining. Consequently, the zig-zag phenomenon indicates the presence of flashing action during joining.

The bonding was not perfect when the welding was heated to temperature of $1373 \mathrm{~K}$ in $10 \mathrm{~s}$ near the bond as shown in Fig. 6(a). Few attachments among austenite phases were noted but the bonding among ferrite phases is occasional. The microstructure demonstrates solid state bonding mechanism among the austenite grains when the heating time increased to $20 \mathrm{sec}$ (Fig. 6(b). The austenite phase elongates and continues to other sample, and the joining becomes flawless. However, bonding among ferrite phases and ferrite to austenite phases are insufficient. When the heating time is further increased to $30 \mathrm{sec}$, various fine grains are noted along the joining line (Fig. 6(c). This is due to longer flash action in slow heating.

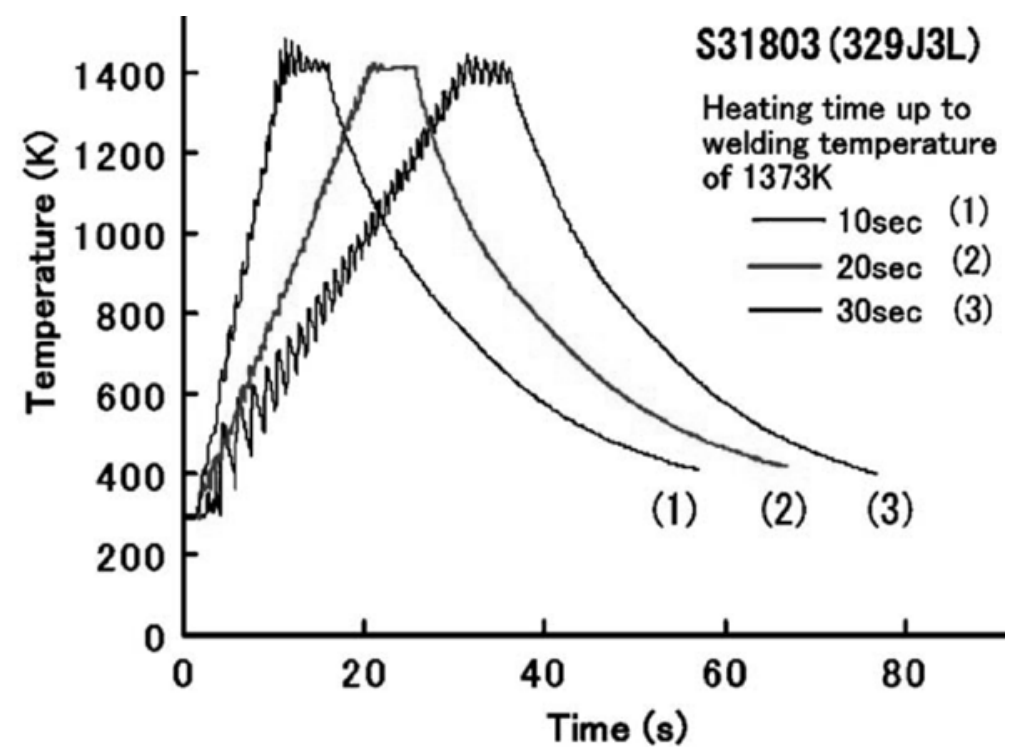

Fig. 5 Temperature-time curves of flash butt welding for DSS [38] 

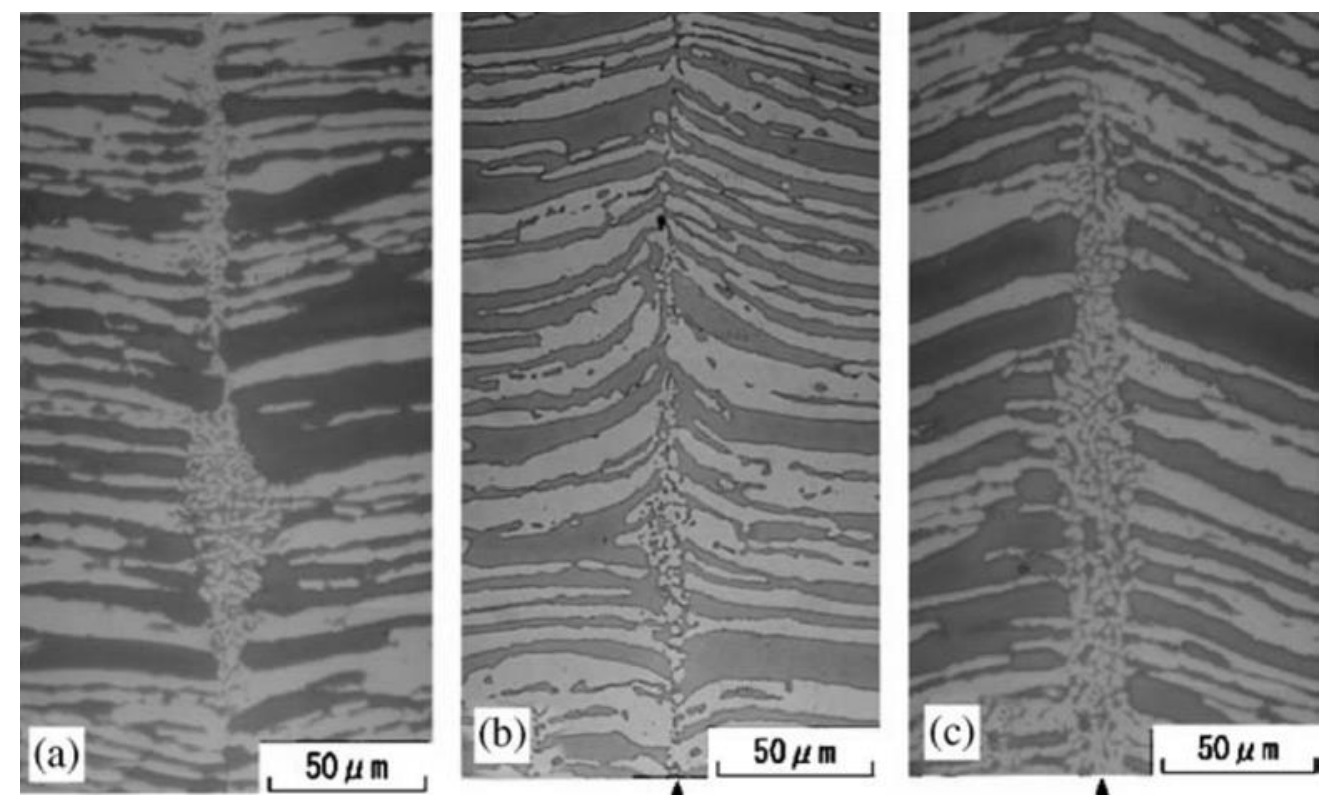

Fig. 6 Bonding interface of 329J3L DSS holding time: (a) 10, (b) 20, (c) $30 \mathrm{sec}$ [38]

Kuroda and Shimada [39] also noted temperature fluctuation during welding the super DSS with $\mathrm{Zr}$-based metallic insert. This shows the presence of micro flashing during this kind of welding. A narrow layer of uniform thickness intermetallic compound, such as $\mathrm{ZrCr}_{2}$ forms in between the DSS and the Zr-based insert. The Zr-based material became liquid phase at higher heat which obtruded outside of the specimen. The projection discharged oxide films on the joining faces and the metallurgical bonding occurs between fresh surfaces. The joining of Zr-based metallic glass with ferrite phase as well as austenite phase in super duplex stainless steel were successful [39].

\section{Tungsten inert-gas welding}

Tungsten as long lasting electrode and inert gas for shielding arc are main components in tungsten inert-gas (TIG) welding [25, 40, 41] where the tungsten electrode incurs an electric arc with the workpiece material to generate the heat required to melt down which is shielded by an inert gas [42-45]. The trustworthiness and properties of the TIG welding are superior to that of any other arc welding methods [46, 47]. Duplex type filler material can be used during TIG welding of duplex stainless steel. This produces more austenitic structure at the TIG WM compare to other types of welding where no filler material is used [48]. In addition, application of nitrogen as backing gas substitutes the loss of $\mathrm{N}_{2}$ at the time of melting and solidifying steps $[49,50]$. 
The picture of fusion zone of 2205 DSS is shown in Fig. 7 which shows that the structure of this zone comprises of austenite phase precipitated within ferrite phase where solidified substructure borders are visible due to quick dispersion of alloying and contaminating elements. Badji et al., [51] divided the heat affected zone (HAZ) into partially annealed and overheated zones. The overheated zone (very near to the fusion boundary) consists of a lesser quantity $(25 \%)$ of austenite compare to the melted and partly annealed regions which is because of the too high topmost temperature in this zone. The phase transformation of this area takes place partially during cooling where the time is insufficient for chromium to disperse all through the ferrite phase. The partly heat treated area of the HAZ consists of substantial development of grain compare to that of base metal (Fig. 8). It seems that the heating of this portion of the HAZ takes place above the solution annealing temperature and large amount of ferrite transforms into austenite on cooling. Generally, the central region which experience slower cooling rate compare to the fusion boundaries contains high amount of austenite.

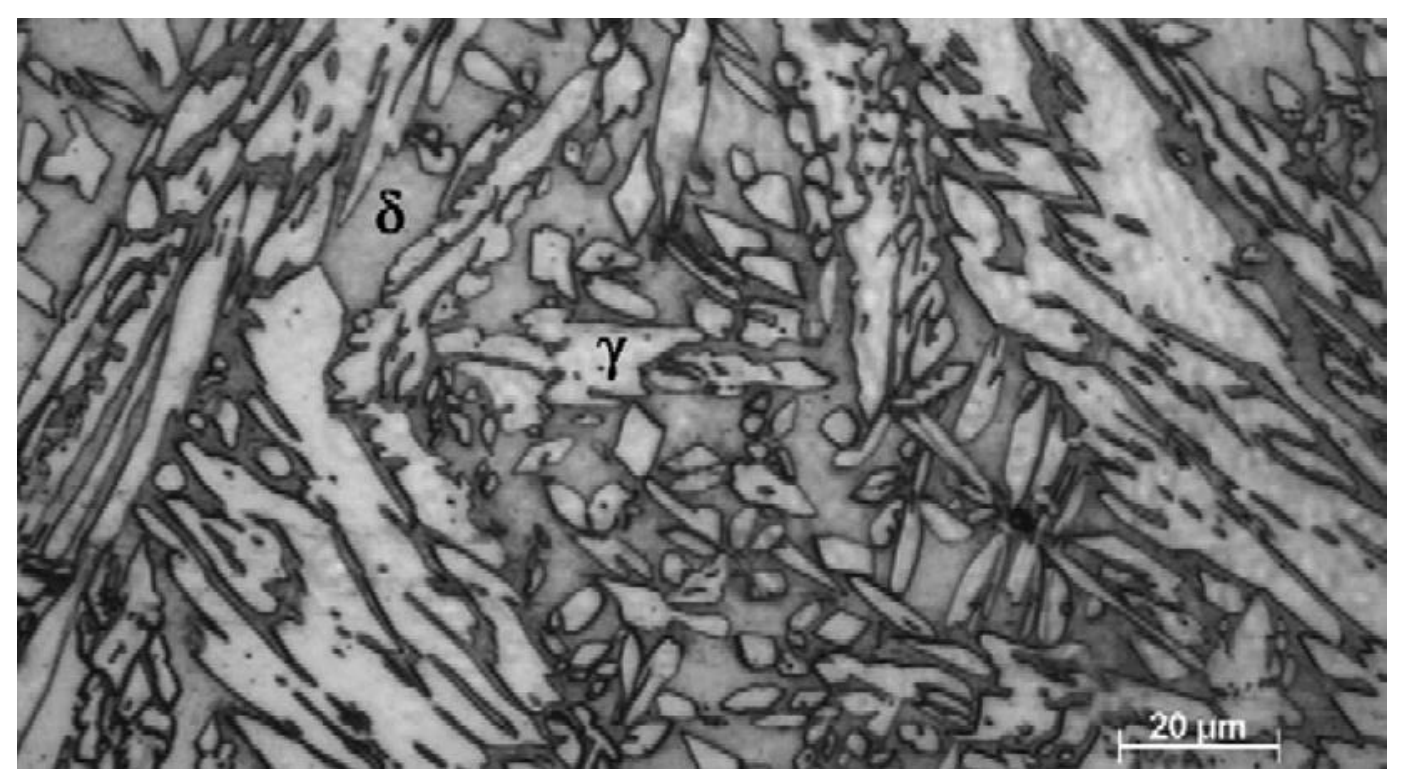

Fig. 7 Fusion area in 2205 DSS [51] 

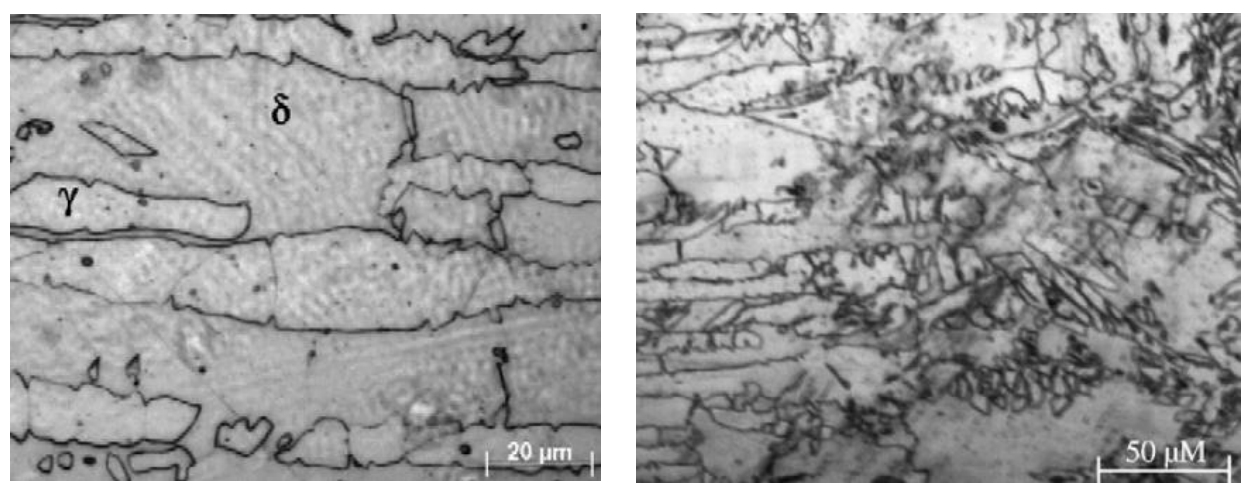

Fig. 8 Structures of (a) partially annealed and (b) overheated part of the HAZ [51].

Nitrogen gas in TIG welding generates thick austenitic phase in the WM (weld metal) as it has a strong austenite forming power. This may introduce nitrogen in WM [52] which was confirmed by Taban [48] with the ferrite content measurements of $30-35 \%$ in the WM by TIG. It is already mentioned that the amount of ferrite is controlled by the composition of $\mathrm{WM}$, the rate of cooling and heat input during welding [53]. The amount of heat applied in TIG welding generally varies from 3.5 to $4.1 \mathrm{~kJ} / \mathrm{mm}$ which is higher than the upper limit $(3.45 \mathrm{~kJ} / \mathrm{mm})$ endorsed by the producers of steel [48]. Thus, the higher heat input deteriorates behaviours of the weldings. However, these can be improved by reducing the runs of welding which ultimately reduce the number of heating and cooling cycles while heating was done to a certain limit of temperature [54]. In addition, Badji et al.,[51] annealed the WM, HAZ, and $\mathrm{BM}$ of $2205 \mathrm{DSS}$ at $850^{\circ} \mathrm{C}$ and noted the sigma phases at the interfaces of ferrite-austenite phases. These interfaces are privileged nucleation locations for the dissimilar formation of intermetallic compounds. The sigma structures in DSS form from the breakdown of $\delta$ ferrite by eutectoid conversion and it grows on the neighbouring $\delta$ ferrite phases after the nucleation process. The precipitation of $\mathrm{Cr}_{23} \mathrm{C}_{6}$ carbides also occurs first at the $\delta-\gamma$ interfaces, and develops on the $\delta$ ferrite grains. The formation and development of $\mathrm{Cr}_{23} \mathrm{C}_{6}$ carbides are supplemented through movement from interfaces of $\delta-\gamma$ structures into the $\delta$ phase [51]. No intermetallic phases were noted and the microstructure comprises ferrite and austenite phases after one hour $1050{ }^{\circ} \mathrm{C}$ anneal. The grain size of $\delta$ ferrite increases significantly compared to austenite grain when the annealing temperature increases from 1050 to $1200{ }^{\circ} \mathrm{C}$ though the destruction of the unique banded structure was noted at this temperature range [51].

The effects of various gas on the microstructure of the welds were investigated by Sathiya et al., [46]. Usually nitrogen is lost and presence of the element that stabilizes ferrite is noted when the shielding gas argon is applied in GTAW (gas tungsten arc welding) joints. This 
causes uneven balance in the two phases. Thus higher percentage of ferrite is noted (shown in Fig. 9(a)) because of the higher amount of Mn. Nitrogen plays an important role as an active stabilizer of austenite and the weldability of duplex steel is enhanced by adding this element at raised temperature $[55,56]$. The austenite phase is generated in three modes from ferrite. These are allotrimorphs, Widmanstätten side-plates and intragranular precipitates which depend on the applied heat and temperature cycles [46]. The required amount of nitrogen can be maintained by selecting right amount of heat and temperature cycles to reduce the difference between ferrite and austenite content in the Ar-shielded welding compared to that of He-shielded welding. In addition, the grains of the Ar-shielded weld metal are of betterquality (Fig. 9(a)). The Fig. 9(d) demonstrates that the austenite in the weld metals are either intragranular precipitates or Widmanstätten which are diagonal to the long-axis. Higher amount of Widmanstätten austenite in the helium-shielded welding than that in Ar-shielded welding is because of the energy-rich arc in helium-shielded welding.

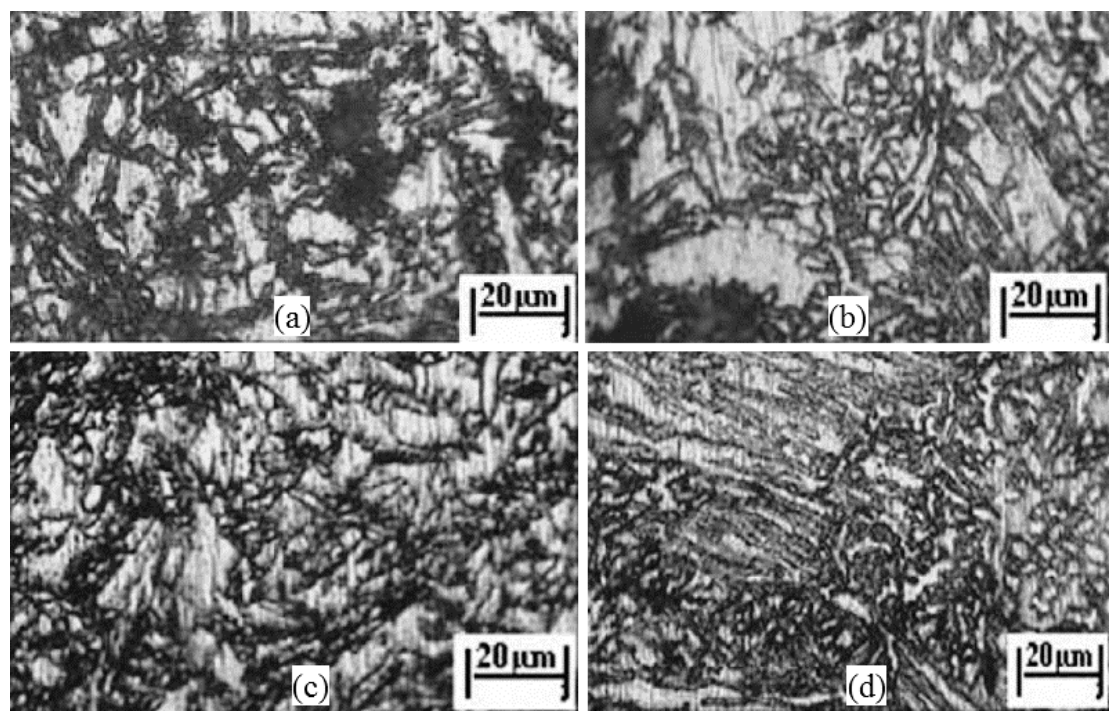

Fig. 9 (a) Ar-shield weld metal, (b) Ar-shield heat affected zone, (c) He-shield weld metal (d) He-shield heat affected zone [46]

Conventional TIG welding can be improved by activated flux. This is known as activated TIG welding. Oxide, chloride, and fluoride powders are generally are dissolved into acetone or ethanol to make an activating flux [57]. This enlarges the penetration by $200-300 \%$ [58, 59] which reduces the weld time, costs and variation of base material constituents. Chern et al.,[57] studied variation of the autogenous TIG welding process by using thin layer of the flux made of oxides of $\mathrm{Ti}, \mathrm{Mn}, \mathrm{Si}, \mathrm{Mo}$, and $\mathrm{Cr}$ to $2205 \mathrm{DSS}$. The structure of the hot rolled 2205 duplex stainless steel plate consists of $45.9 \%$ and $54.1 \%$ ferrite and austenite 
respectively. The percentages of these two phases in the DSS with various types of flux after twelding are shown in Fig. 10. It shows that the percentage of ferrite improved from 45.9 to $63.4 \%$ after TIG weld without flux. This is due to solidification of this material as delta ferrite. Due to higher rate of cooling, the conversion to austenite from delta ferrite was incomplete which resulted higher amount of ferrite in weld metal. The oxide fluxes raise the percentage of ferrite from 52.3 to $57.5 \%$ in activated TIG weld metal which is lesser when compared with that which was generated with no flux. This was resulted because of the increased applied heat which reduces the rate of cooling. Thus, the conversion to austenite of delta ferrite attains the equilibrium phases and results in lower amount of ferrite. Close percentages of ferrite $(52.3 \%)$ and austenite $(47.7 \%)$ in the weld metals were note when $\mathrm{SiO}_{2}$ flux was used [57].

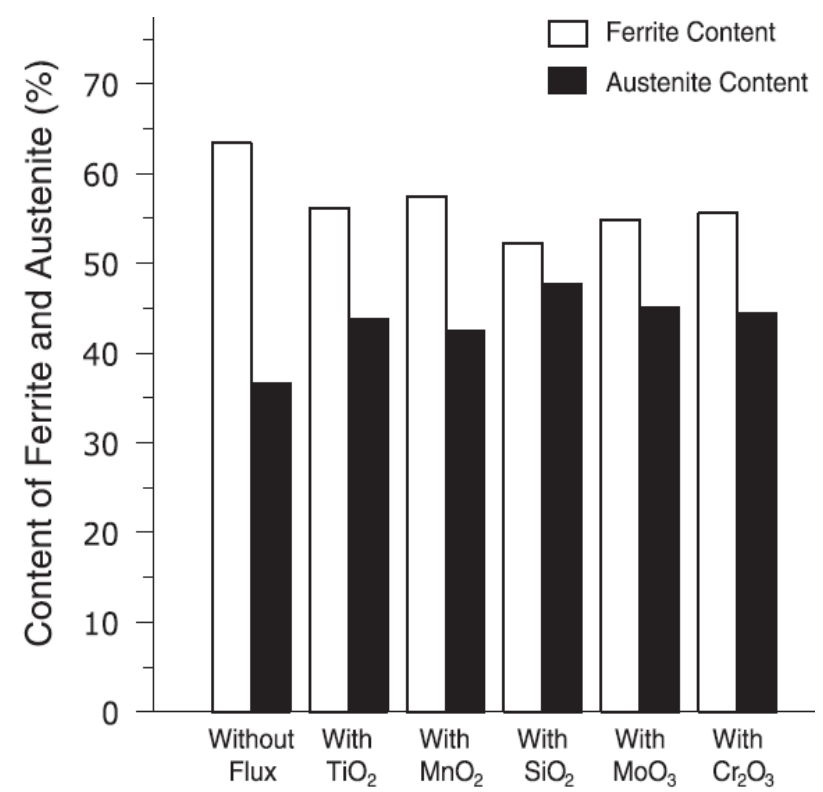

Fig. 10 Percentages of ferrite and austenite with different types of fluxes [57]

Fig. 11(a) shows the different welding regions (BM, HAZ and WM) in a GTA welded joint where welding parameters were current $110 \mathrm{~A}$, voltage $12 \mathrm{~V}$, speed of welding $0.15 \mathrm{~m} / \mathrm{min}$ and the rate of shielding gas (argon) flow $151 /$ min [10]. A relatively wider HAZ with the coarser grained zone next to the fusion line was noted. This was brought about from nearly thorough austenite dissolution due to heating and successive growth of ferrite. The HAZ comprises of bigger ferrite with uninterrupted grids of austenite and intragranular austenite precipitates at the grain boundaries of ferrite (Fig. 11 (a) and (c)). The Widmanstätten austenite which deposited from the austenite grain periphery was noted in the weld metal. A crystallographic orientation with the ferrite was maintained by the intragranular austenite 
which nucleates favourably along prior solidified subgrain boundaries. These are considered to be normal microstructures of GTA weld [10,60].
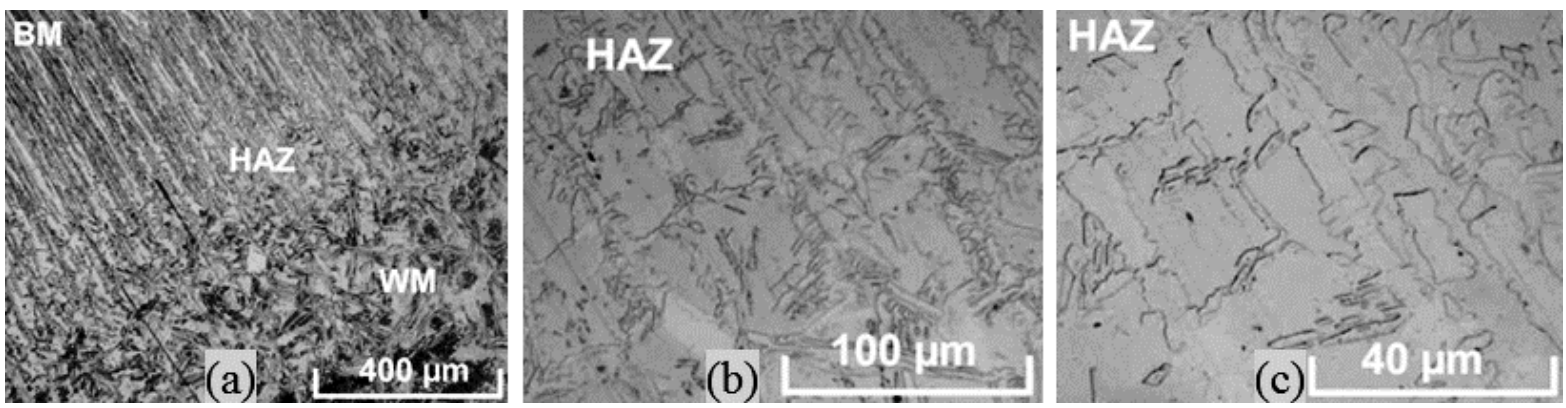

Fig. 11 Optical micrographs of GTA welded joint cross section. (a) Joint different regions (BM, HAZ and WM) (b) and (c) Higher magnifications for HAZ region [10].

Eghlimi et al., [61] cladded super DSS filler metals on high strength steel substrates by the tungsten arc welding where pulsed and constant currents were used to characterize the pulsed current effect on the phase composition and microstructure of the claddings. In this case two successive layers were deposited on the substrate to reduce the dilution effect in the top layer. The microstructures of the claddings in the top-surface produced by the pulsed and constant currents are shown in Fig. 12. Generally higher cooling rate occurs in the pulsed current cladding which retards the transition from ferrite to austenite at $600-1000{ }^{\circ} \mathrm{C}[62,63]$. On the other hand, the constant current $\left(73^{\circ} \mathrm{C} / \mathrm{s}\right.$ induces lower cooling rate $\left(55^{\circ} \mathrm{C} / \mathrm{s}\right)$ which facilitates the diffusion rate of alloying elements and generates higher quantities of austenite and may help the precipitation of the intermetallic compounds [61]. 

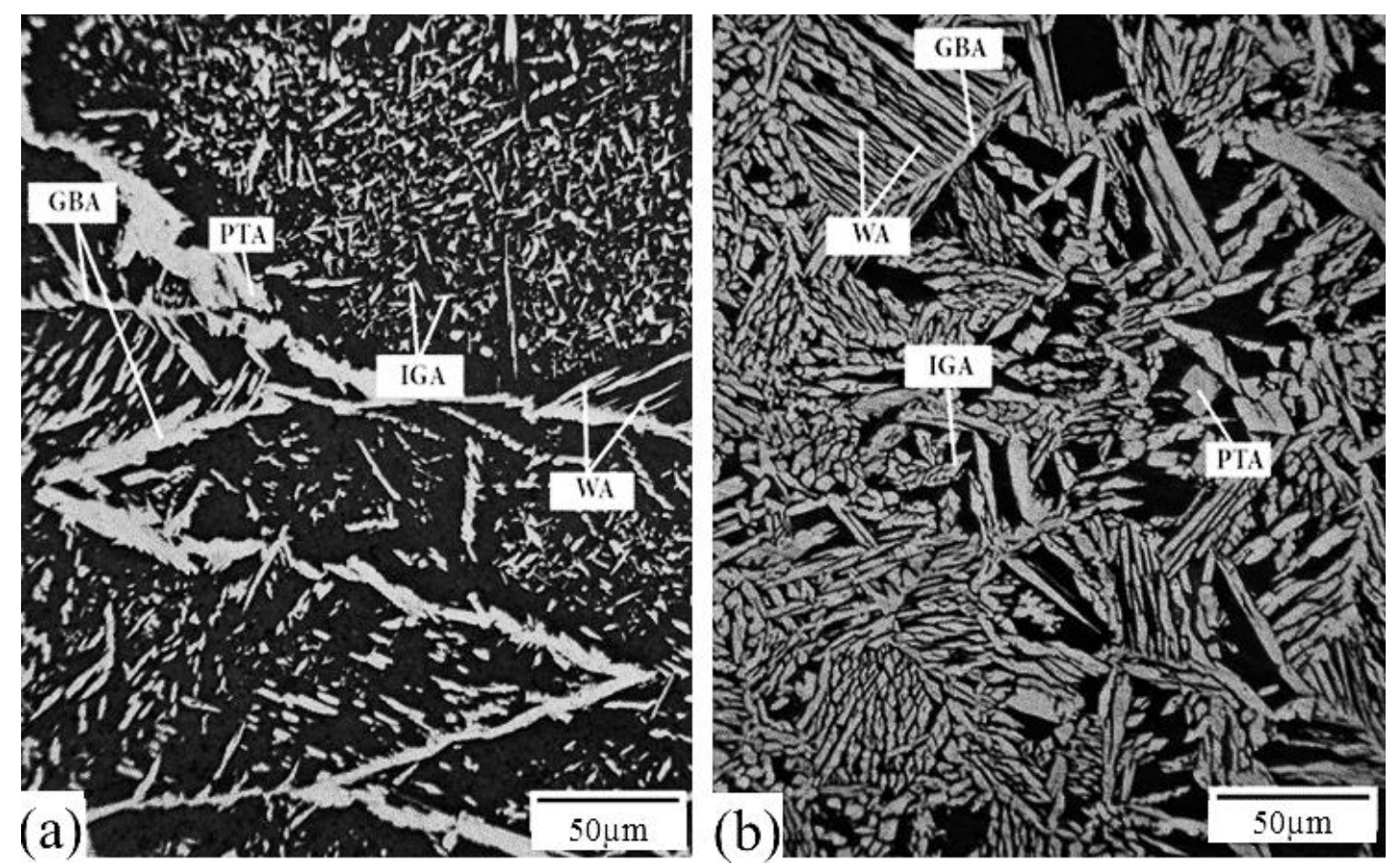

Fig. 12 Representative top surface microstructure of claddings: (a) Pulsed current and (b)

Constant current. Where, PTA - partially transformed austenite, IGA - intragranular austenite, WA - Widmanstätten austenite and GBA - grain boundary austenite [61]

Underlying and side weld metals are reheated by deposition of the subsequent passes in multi-pass welding. The thermal cycles in the reheated regions are very similar to those of the heat affected zone. Thus, the presence of intragranular and acicular morphologies of secondary austenite is expected. The austenites precipitated during the initial weld cooling and subsequent reheating are referred as primary austenite $\left(\gamma_{1}\right)$ and secondary austenite $\left(\gamma_{2}\right)$ respectively. It is proved that $[64,65]$ the solidification mode of SDSSs is actually ferriticaustenitic and 15-20\% of the austenite phase remains when the alloy is reheated to solidus temperature. That remainder of primary austenite $\left(\gamma_{1}\right)$ is usually referred to as partially transformed austenite (PTA) which is beneficial $[66,67]$ as it can obstruct the segregation of chromium and molybdenum at solidus temperature and limit the grain growth [61].

The secondary austenite with different morphologies also forms such as, the allotriomorphic grain boundary austenite (GBA) which is reported to re-precipitate at 1350 to $800{ }^{\circ} \mathrm{C}[3]$. The side-plate Widmanstätten austenite (WA) may initiate from the allotriomorphic austenite[68] and/or from PTA [69] if enough time is given. WA can form by heating SDSSs at in the range of 650 to $800{ }^{\circ} \mathrm{C}$ where diffusion is fast $[70,71]$. The intragranular austenite (IGA) may form within $\delta$-ferrite grains in multi-pass welding which requires more 
undercooling as a driving force compare to GBA and WA[16] because of higher activation energy for lattice diffusion. Thus the growth of IGA is less compare to GBA and WA phases as shown in Fig. 12. The predominant IGA precipitation takes place in $1000-1100{ }^{\circ} \mathrm{C}$ for super DSSs [65]. The Fig. 12 shows that the total amount of the reformed austenite is higher when constant current is used. With only $30 \%$ cooling rate the pulsed current causes a considerable difference in austenite fraction[65]. By comparing the microstructures, it can be seen that the constant current develops more GBA and WA, but less IGA [61].

The rate of cooling and amount of undercooling control the structure of the fusion zone significantly in pulsed GTAW when similar amount of heat is input [72-75]. The cross sections of the weld by using different parameters under the same heat input are given in Fig. 13. It presents that the depth-to-width ratio of weld for pulsed DC is around 0.252 (Fig. 13(b)) which is bigger than that (0.238) of unpulsed DC weld (Fig. 13(a)) both are at same temperature of $25^{\circ} \mathrm{C}$. The ferrite phases are generally columnar in the solidified metal for unpulsed DC weld (Fig. 13(a)). These ferrite phases tend to be equiaxed (Fig. 13(b) and (c)) with the application of pulsed DC welding and/or the faster rate of cooling. However, the Fig. 13(c) that the microstructure contains almost fully equiaxed grains for pulsed DC weld at $7{ }^{\circ} \mathrm{C}$. Table 2 compares the GTAW welds with different parameters. Around $37 \mathrm{vol} \%$ of austenite can be achieved in the absence of nitrogen or post-weld heat treatment when the weld pool solidifies at a faster rate of cooling $\left(139{ }^{\circ} \mathrm{C} / \mathrm{s}\right)$. The pulsed weld metal at $7{ }^{\circ} \mathrm{C}$ contains considerable quantity of needed intragranular austenite (IGA) within the matrix of the ferrite phase in addition to Widmannstätten austenite (WA) and grain boundary austenite (GBA). This brings about even dispersal of hardness and other mechanical properties [72].
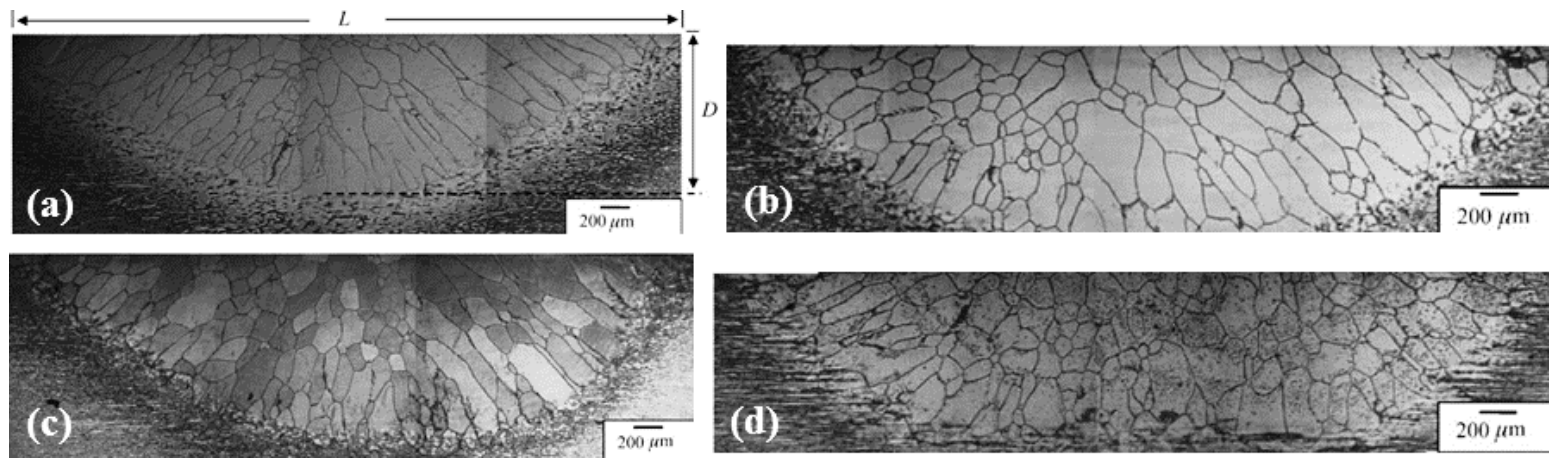

Fig. 13. The $L / D$ in weld sections of the bead-on-plate for 2205 DSS: (a) $1 / 0.238 \mathrm{dc}$ at $25{ }^{\circ} \mathrm{C}$, (b) $1 / 0.252$ pulsed dc at $25^{\circ} \mathrm{C}$, (c) $1 / 0.275 \mathrm{dc}$ at $7{ }^{\circ} \mathrm{C}$, (d) $1 / 0.244$ pulsed dc at $7{ }^{\circ} \mathrm{C}$ [72]. 
Table 2 Welding paramers, $\gamma$ content and rate of cooling for 2205 DSS [72]

\begin{tabular}{lcccc}
\hline Welding condition & $\mathrm{dc}$ at $25^{\circ} \mathrm{C}$ & Pulsed dc at $25^{\circ} \mathrm{C}$ & $\mathrm{dc}$ at $7{ }^{\circ} \mathrm{C}$ & Pulsed dc at $7^{\circ} \mathrm{C}$ \\
\cline { 2 - 5 }$\gamma$ Content $(\%)$ & 11 & 19 & 27 & 37 \\
Cooling rate $\left({ }^{\circ} \mathrm{C} / \mathrm{s}\right)$ & 59 & 68 & 102 & 139 \\
$\begin{array}{l}\text { Equiaxed ferrite grains } \\
\text { size }(\mu \mathrm{m})\end{array}$ & 124 & 81 & 129 & 102 \\
$\begin{array}{l}\text { Columnar ferrite grains } \\
\text { size }(\mu \mathrm{m})\end{array}$ & Long $=501$ & Long $=336$ & Long $=334$ & Long $=266$ \\
$\begin{array}{l}\text { Average ferrite grains } \\
\text { size }(\mu \mathrm{m})\end{array}$ & short $=121$ & short $=102$ & short $=89$ & short $=104$ \\
\cline { 1 - 3 } & 134 & 102 & 109 & 107 \\
\end{tabular}

According to Korra et al.,[45] the range of parameters, such as current 202.817 to 208.678 A, welding speed 119.997 to $120 \mathrm{~mm} / \mathrm{min}$, and arc gap 1.00 to $1.01107 \mathrm{~mm}$ are the optimal factors for best weld bead geometry during TIG welding of 10-mm-thick 2205 DSS plates.

\section{Submerged arc welding}

This process produces superior welds in ferrous and non-ferrous metals variety of depths. In this case, the arc is formed due to continuous passing of electric current through a welding tip and the workpiece $[76,77]$. A flux in powder form covers the arc, welding tip and the new joint. Thus the welding operation is protected from atmospheric contamination and, the smoke and fume are stopped from coming out [78-80]. The intermediate phases, such as carbide phases and nitride phases may precipitated during welding of 2205 DSS at the temperature range of $800-475{ }^{\circ} \mathrm{C}$ [81]. The $\sigma$ phase which is an intermetallic compound with high content of $\mathrm{Cr}$ and Mo elements also grows through the interchange of alloy elements and the rearrangement of ferrite and austenite phases. The $\sigma$ phase is a hard and brittle which precipitates at ferrite-austenite interface or within ferrite, and grows up in ferrite [69] reduces the ductility, toughness and resistance to corrosion of the 2205 DSS welded joints.

Luo et al., [82] introduced post weld heat treatment (PWHT) to submerged arc welding of 2205 DSS. They did not note any porosity, slag, crack and other welding defects in macrostructure before heat treatment. However, coarse columnar grains were formed in the welding centre zone and this changed to fine dendrite grains in the fusion zone away from the welding centre. The columnar grains which change the performance of welding centre zone are produced due to composition segregation [83]. Fig. 14 shows the microstructures of the submerged arc welding of 2205 DSS before and after heat treatment. The segregation of second phases occurs in both cases. However, the concentration of segregation and content of 
o phase increases significantly after heat treatment. Before heat treatment, the $\delta$ phase is composed of a strip and block style microstructure, the $\gamma$ phase is of the feathery characteristic, and there has little amount of $\sigma$ phase at the weld centre zone, and the amount of $\sigma$ phase is relatively large with continuous distribution at the fusion edge zone. All these affect mechanical properties and resistances to corrosion of 2205 DSS weldings inversely. This is due to the diffusion of certain elements and redistribution of phases during welding and heat treatment processes of 2205 DSS. Cr and Mo elements may stimulate the formation of the $\sigma$ phase. The nucleation rate of $\sigma$ phase is proportional to temperature and inversely proportional to the grain size of $\delta$ ferrite. The diffusion rate of $\mathrm{Cr}$, Mo and other elements is faster at higher temperature. This encourages the production of $\sigma$ phase in the fusion edge area. The balanced conditions at the weld centre zone increase the segregation of $\mathrm{Ni}, \mathrm{Fe}$ and $\mathrm{Cr}$ around $\sigma$ phase regions. This stimulates the precipitation of $\gamma$ and $\delta$ phases, decompose of $\sigma$ into $\gamma$ and $\delta$ phases, and causes the segregation of $\gamma$ and $\delta$ phases [82].

The amount of $\gamma$ phase is decreased at the weld centre zone after heat treatment though the amounts of $\delta$ and $\sigma$ phases increase (Fig. 14(c-e)). At the fusion edge zone $\sigma$ phase is almost extinct, the number and size of $\gamma$ and $\delta$ phases increased where the $\delta$ phase forms a continuous meshed microstructure and the $\gamma$ phases are separated by the $\delta$ phase matrix. The loss of the $\sigma$ phase improves the mechanical properties and resistance to corrosion [82]. The welding pass stimulates the precipitation of $\sigma$ phase in the fusion edge zone and little amount of $\sigma$ phase and $\delta$ phase precipitate at the weld centre zone before heat treatment $[46,83]$. The larger $\sigma$ phase disappears in the fusion edge zone after heat treatment though $\sigma$ and $\delta$ phases increase little and $\gamma$ phase decreases in the weld centre zone.

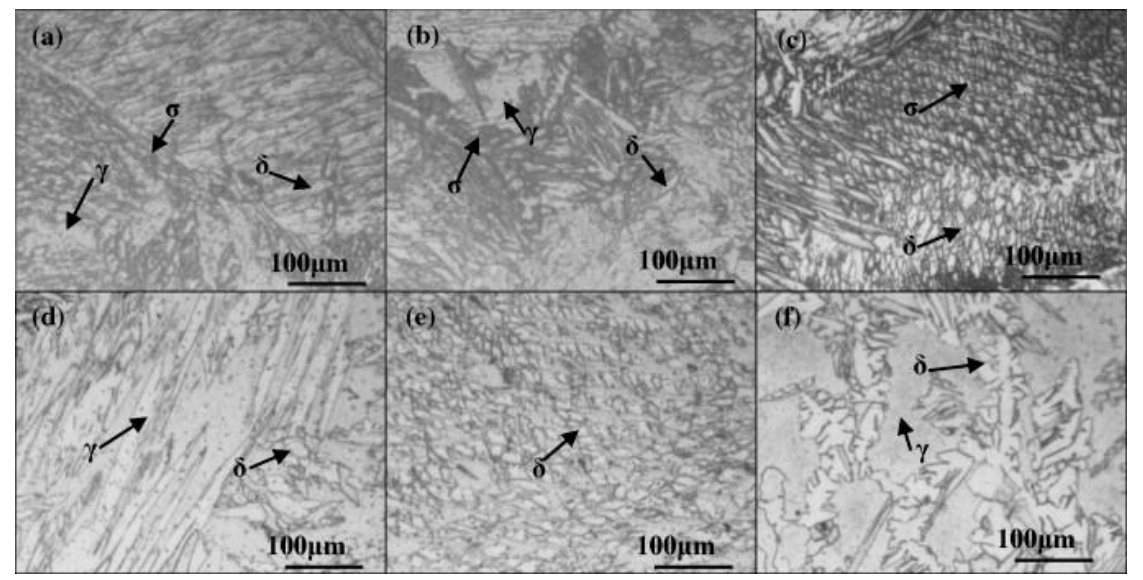


Fig. 14 Microstructures of 2205 DSS welded joints: (a) weld center zone without PWHT; (b) fusion edge zone without PWHT; (c) weld. center zone with PWHT; (d) weld center zone with PWHT; (e) weld center zone with PWHT; (f) fusion edge zone with PWHT [82]

McPherson et al., [84] used submerged arc welding to 2205 DSS where the weld structure were comprised of an acicular austenite and ferrite structures. The DSS welds did not show any precipitation in the weld metals. There were occurrences of chi-phase in the HAZ, but these were comparatively occasional [84]. It seems to be noteworthy opportunity to apply higher dilution submerged arc welding of 2205 DSS. Higher dilution double-sided submerged arc welding of $20 \mathrm{~mm}$ thick DSS produces satisfactory products. Generally, the single sided welding process causes distortion and the double-sided process refutes distortion of welded parts [84].

\section{Friction stir welding}

Friction stir welding which is a solid-state joining technologies has attracted considerable attention to get rid of disadvantages of fusion welding processes of duplex stainless steel [85]. Friction stir welding also demonstrated the capability to reduce difficulties of fusion welding processes in various types of steels, such as carbon steels (carbon wt\% $\leq 1.02$ ) [86], mild steels [87], DH36 steel [88] and stainless steels [89]. Generally, sound joints can be obtained by friction stir welding when the speed of welding $\leq 200 \mathrm{~mm} / \mathrm{min}$. The defects like groove may form because of inadequate heat during friction stir welding process where the material is unable to flow easily in the tool pin gap [90] and these worsen the weld properties [91].

The pictures (Fig. 15) of various sections of friction stir weld show three distinct microstructure regions of the weldment. Those are (i) base metal (BM), (ii) thermomechanically affected zone (TMAZ) and (iii) stir zone (SZ) [85]. The heat-affected zone (HAZ) shows embedded white austenite $(\gamma)$ islands in ferrite $(\alpha)$ where extended shaped $\alpha$ and $\gamma$ have 51 and 49 volume percentages, respectively. The stir zone contains smaller equiaxed grains. The TMAZ is distorted because of mechanical deformation and heating. The TMAZ-SZ interfaces in the front of the welding tool are much distinguished than those in the back side which causes unevenness in the weld [15, 92]. The stirring effect of the welding tool causes a severe deformation and re-orientation of grains in TMAZ next to the SZ-TMAZ interface [85]. 
Fig. 16 shows that fine-grained $\alpha$ and $\gamma$ micro-duplex structure forms in welding speed of 50, 100, 150 and $200 \mathrm{~mm} / \mathrm{min}$. Duplex stainless steel generally needs to follow complex thermomechanical processing to form micro-duplex structure [93]. The stir zone microstructures obtained by Saeid et al., [85] reveal that fusion stir welding process generates micro-duplex structure in a simple way and can potentially replace time-consuming and complicated thermo-mechanical processing [94].

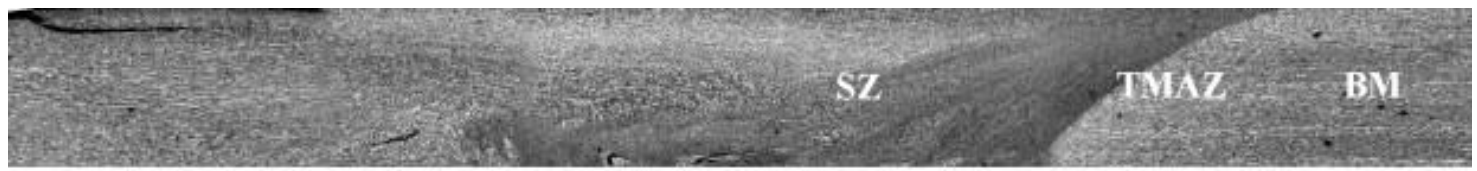

(a)

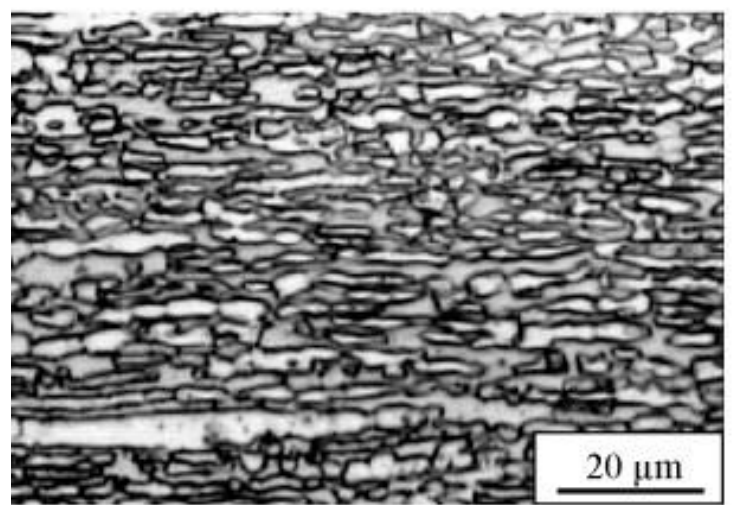

(b)

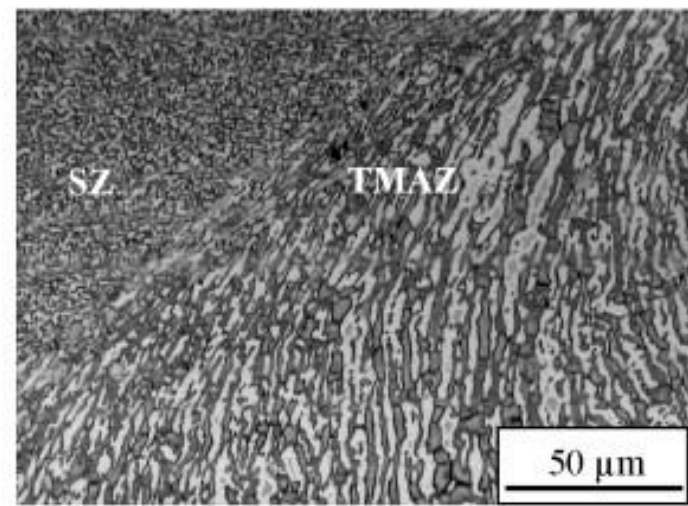

(c)

Fig. 15 Structures of friction stir weld in duplex 2205 (600 rpm and $200 \mathrm{~mm} / \mathrm{min}$ ): (a) weld macrograph, (b) magnified base metal and (c) magnified interface of SZ and TMAZ [85].

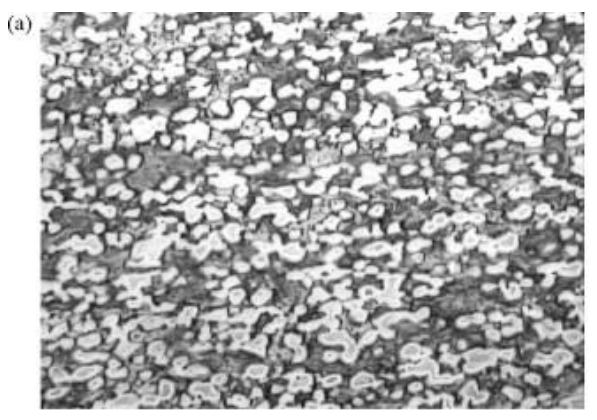

(c) $Y$

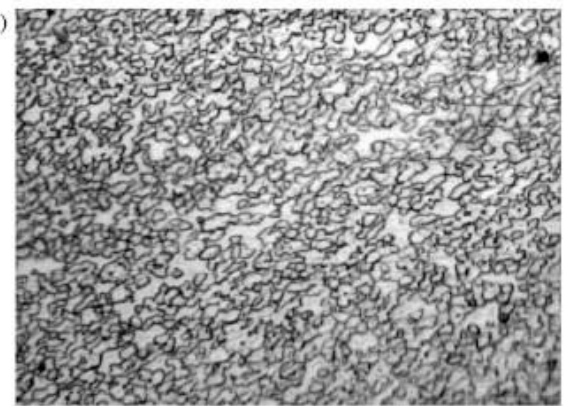

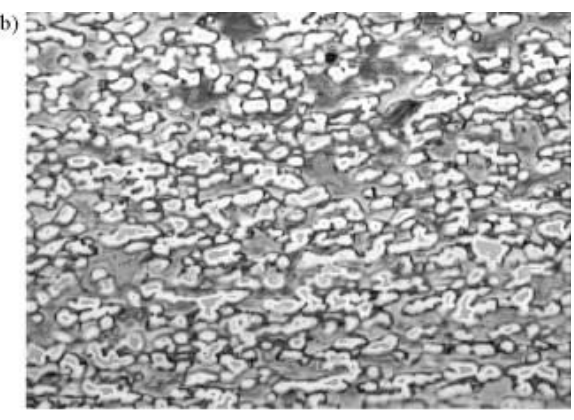

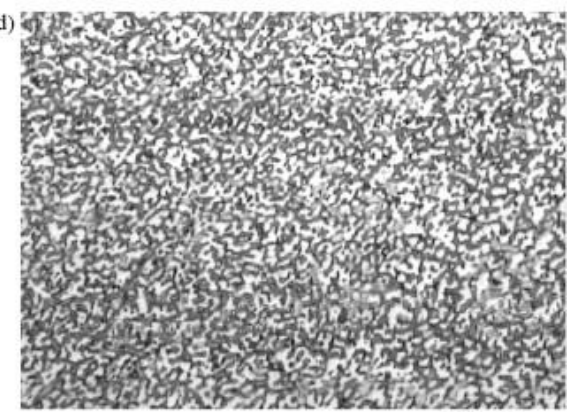

$20 \mu \mathrm{m}$ 
Fig. 16 The grains in the stir zone in 2205 duplex stainless steel at various speeds: (a) 50, (b) 100, (c) 150 and (d) $200 \mathrm{~mm} / \mathrm{min}[85]$.

\section{Plasma arc welding}

The smaller heat affected zone and high penetration/width ratios are the main advantages of plasma arc welding (PAW) [53]. This method uses the electric arc which is produced through an electric gap of a reusable tungsten electrode and workpiece where high concentrated energy (plasma gas and arc) is delivered from a restricted opening [95-97]. This method can be used as conduction (melt-in welding) and keyhole modes. The conduction mode is typically accepted in traditional welding processes [98]. The keyhole mode is applied for limited varieties of metal depth $(2.5-6 \mathrm{~mm})$. The right arrangement of orifice gas flow, welding speed and current allow quicker welding than gas tungsten arc welding with full dispersions and makes keyhole forming possible [53].

Fig. 17 shows the conduction mode plasma arc weld joints where HAZs are narrow (around $450 \mu \mathrm{m}$ ) due to medium energy input (around $7000 \mathrm{~J} / \mathrm{cm}$ ). However, considerable ferrite grain growth is exhibited (Fig. 17(a)) in this case, which (pointed as A) affects the succeeding epitaxial development of the columnar structure of ferrites in the fusion zone (pointed as B in Fig. 17(b)). The precipitation of secondary austenite as Widmanstätten needles (pointed in Fig. 17(b)) from the ferrite grain boundaries was boosted in the fusion zone. The quantity and size of the needles were also improved with the consumption of more energy [53].
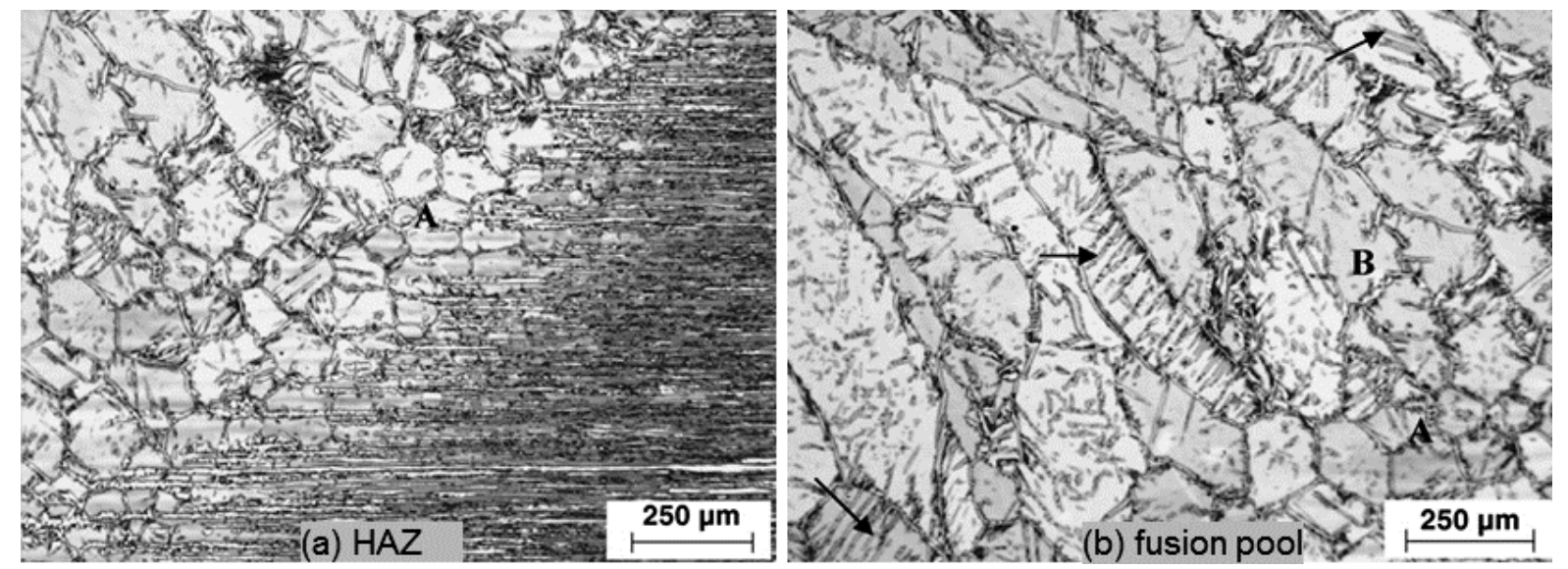

Fig. 17 Structure of the conduction mode weld (7380 J/cm energy input) [53].

Urena et al., [53] used Ferritoscope to estimate the volumetric proportion of $\alpha$ and $\gamma$ phases. A higher ferrite content of more than $60 \%$ was noted predominantly in the fusion zone. The 
net energy input and the upkeep of welding power controls the ferrite content. The increase of the welding speed reduces the ferrite content inside the melting pool. The microstructure at the fusion line from keyhole plasma arc mode with a 75 ampere current, $4 \mathrm{~mm}$ working distance and $45 \mathrm{~cm} / \mathrm{min}$ speed is shown in Fig. 18(a). In this case, the thermal damage was tiny to the DSS sheet and HAZ was only $150-250 \mu \mathrm{m}$ thick. The growth of the grain was very limited though the presence of the banded recrystallized texture was noted. The formation of the microstructure by quasi-equiaxial ferrite with austenite in the borders of grain and a lower amount of austenite needles (Fig. 18(b)) were also noted [53]. The Widsmanstätten austenite formation in the HAZ decreased the dimensions of the columnar ferrite phases generated by epitaxial solidification from the base grain due to the reduced grain development in the HAZ [53]. The intermetallic sigma phases were not detected at lowenergy conditions though the fractional melted areas were noted at grain borders of base metal in addition to intermetallics when the energy input was increased $(3100 \mathrm{~J} / \mathrm{cm})$ by reducing the arc distances $(3 \mathrm{~mm})$.
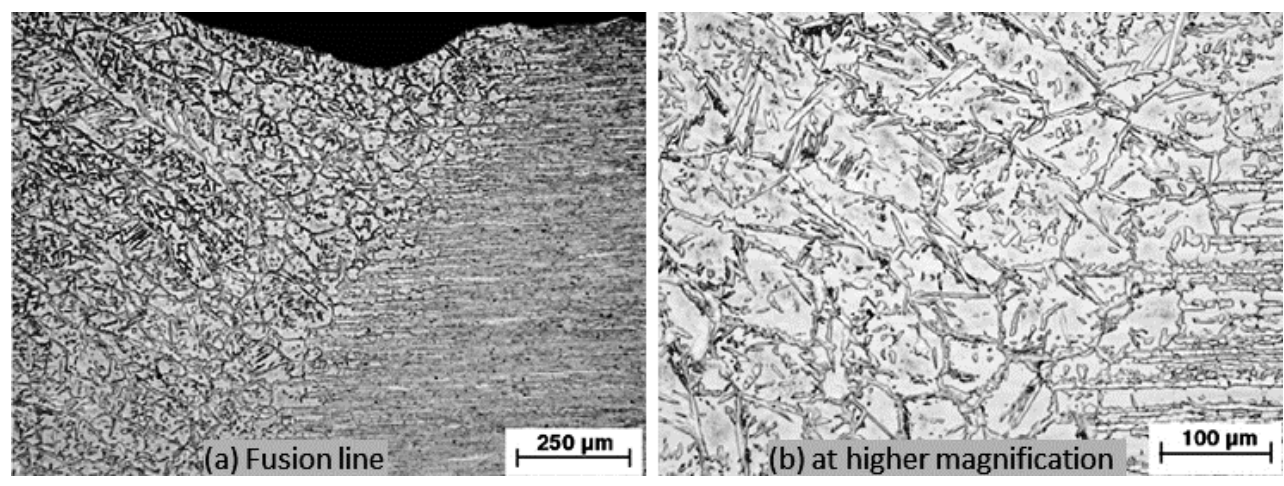

Fig. 18 Fusion line of a keyhole weld (2550 J/cm heat input) structure [53]

The ferritometry measurements confirm that the ferrite contents are around $50 \%$ in the fusion zones of keyhole type welding which are lesser than that in conduction mode welding. The differences were not significant in the ferrite quantity for variation of the energy input. However, the higher portion of ferrite was formed in the central part of the welds due to the shorter working distance between plasma torch and workpiece [53].

Taban [48] used keyhole mode plasma arc welding in DSS where direct current was used in absence of filler metal. The welding was formed by single pass for different heat input $(1.82 \mathrm{~kJ} / \mathrm{mm}$ to $1.96 \mathrm{~kJ} / \mathrm{mm})$ where very pure Ar was used as shielding gas. At low heat input the base metal contains elongated grain structure similar to the produces from rolling where the ferrite and austenite phases are of nearly similar portions. The main solidification part is 
ferrite at the fusion pool. The quick chilling suppressed diffusional transformation to austenite causes primarily ferritic configuration. The structure of welding of these materials can considerably vary from its base metal to the austenitic and martensitic types. The heating near the solidus temperatures induces conversion from austenite to ferrite and it is retained during cooling [99]. The successive epitaxial development of the columnar ferrite depends on the size of HAZ (Fig. 19) [53]. Fig. 19 also shows the subordinate austenite mostly in the weld metal as Widmanstatten needles developing into the ferrite phase [100]. Ferrite content based on the Fischer Ferritscope on the macrosections are $49.3 \%$ in the BM left, 55\% in the left to the HAZ, $61 \%$ in WM, 54\% in the right to the HAZ, and $53.3 \%$ in the right to the BM approximately. The portion of ferrite in WMs are greater than that in BM (almost 50\%) in plasma arc welds as the WM is solidified as delta ferrite and fractional conversion to austenite starts at the ferrite phase borders and carried on intergranularly when it cool off . Thus a smaller amount of austenite was generated in the WM as the weld cools faster [101].

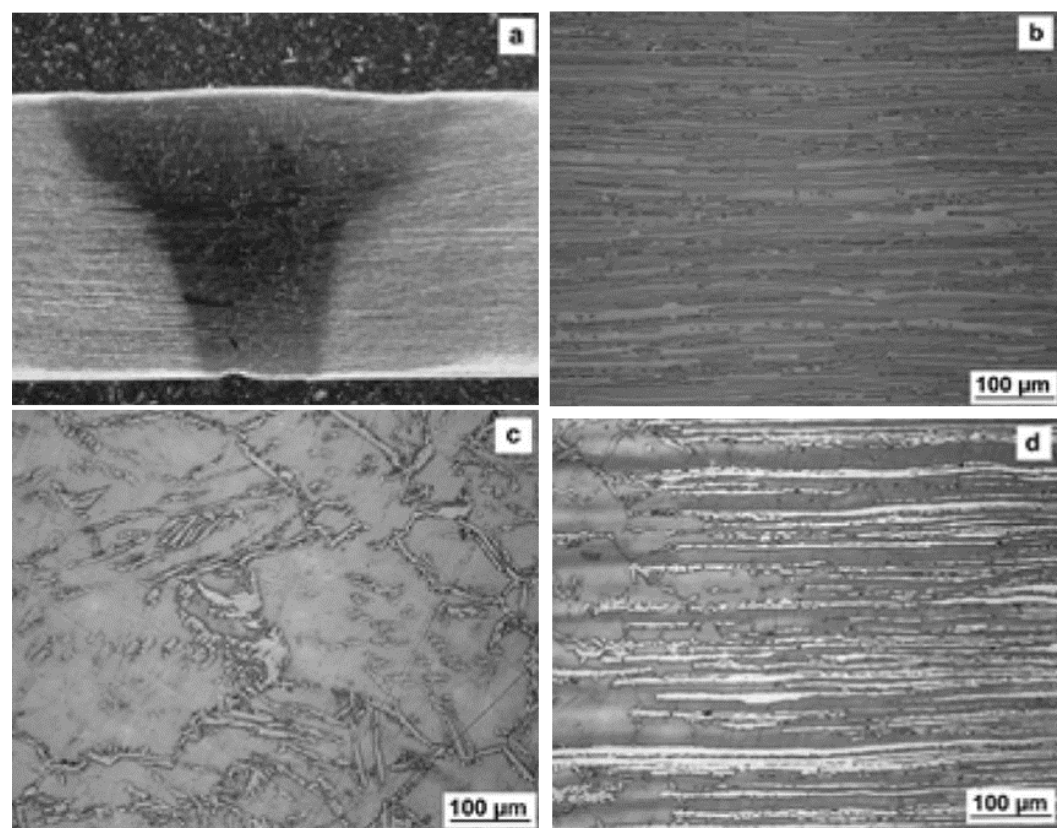

Fig. 19 (a) Macrograph of plasma arc weld; (b) base metal; (c) weld metal; and (d) boundary of weld metal and heat affected zone [48].

Lee et al., [25] investigated and compared the effect of various types of welding, such as metal active gas (MAG), tungsten inert gas (TIG) and laser welding on microstructural, tensile properties and fatigue strength for a DP780 DSS. They found that the welded zone becomes bigger at higher of heat input (MAG > TIG > laser). However, the hardness of the $\mathrm{WM}$ and HAZ increases with cooling rate (laser $>$ TIG > MAG). The laser and TIG welding 
produces higher yield strength of WM than that of MAG due to harder weld metal. The fatigue life of laser and TIG welded steel was similar and better than that of MAG welding. However, all welded materials show worse fatigue properties compared to that of the nonwelded BM.

\section{Conclusion}

The main challenges to obtain optimum fraction of ferrite and austenite phases during welding of DSS are to control the heat input, cooling rate and composition of the workpiece materials/filler materials/shielding gas. The heat treatment of the weld is the last resort to fix the desired balance of ferrite and austenite phases in duplex stainless steel welds. The following conclusions are aroused base on the analysis of the different welding methods of different duplex stainless steel.

(a) Greater fraction of ferrite is generally formed during laser welding of DSS, such as 2101, 2205, and 2304. An acceptable amount of austenite can be formed by a cooling rate of 30 to $10{ }^{\circ} \mathrm{C} / \mathrm{s}$.

(b) It seems that the resistance welding and submerged arc welding have the capability to produce optimum weld structure though further research on this method is required as much information is not available on this method.

(c) Most researches on welding of DSS are noted in the field of tungsten inert-gas (TIG) welding. Generally the ferrite content is low and intermetallic compounds are deposited in the ferrite-austenite interface during the conventional TIG welding. The shielding by argon gas gives better ferrite-austenite structure in the welding. The ferrite-austenite stability of WM and HAZ is better for TIG than that of laser beam welding. However, the extent of WM and HAZ is lesser for the laser beam welding than that of TIG.

(d) The activated TIG welding improves conventional method in terms of the weld depth and ferrite amount by using activating flux. The oxide fluxes $\left(\mathrm{SiO}_{2}\right)$ increase the ferrite content of 2205 duplex stainless steel to $63.4 \%$.

(e) The cladding of duplex stainless steel by TIG does not give expected structure unless it is heat treated. The pulsed DC current gives higher amount of ferrite compare to that of DC current.

(f) Friction stir welding is the only solid state process applied to duplex stainless steel. This method produced a structure of $51 \%$ austenite and $49 \%$ ferrite for 2205 grade duplex 
stainless steel. The time consuming and complex thermo-mechanical processing can be replaced by this method.

(g) The main advantage of the plasma arc welding is the high penetration to width ratio with smaller heat affected zone. In addition, this method is capable to keep the portion of ferrite and austenite structure in the expected range.

\section{References}

1. Davis, J., SM Specialty Handbook: Stainless Steels, ed. J.R. Davis. 1994: ASM International. 576.

2. Svensson, L.F. and B. Gretoft, Properties-microstructure relationship for duplex stainless steel weld metals. Proc. Int. Conf. Duplex Stainless Steel, 1986: p. 22.

3. Chen, L., et al., Influence of cooling rate on microstructure evolution and pitting corrosion resistance in the simulated heat-affected zone of 2304 duplex stainless steels. Corrosion Science, 2012. 58: p. 168-174.

4. Wang, S.-G., G.-P. Dong, and Q.-H. Ma, Welding of duplex stainless steel composite plate: influence on microstructural development. Materials and Manufacturing Processes, 2009. 24(12): p. 1383-1388.

5. Tan, H., et al., Influence of welding thermal cycles on microstructure and pitting corrosion resistance of 2304 duplex stainless steels. Corrosion Science, 2012. 55: p. 368-377.

6. Davison, R. and J. Redmond, A guide to using duplex stainless steels. Materials \& Design, 1991. 12(4): p. 187-192.

7. Nomani, J., et al., Machinability study of first generation duplex (2205), second generation duplex (2507) and austenite stainless steel during drilling process. Wear, 2013. 304(1): p. 20-28.

8. Wang, J., et al., Effect of welding process on the microstructure and properties of dissimilar weld joints between low alloy steel and duplex stainless steel. International Journal of Minerals, Metallurgy, and Materials, 2012. 19(6): p. 518-524.

9. Zhang, Z., et al., Effect of post-weld heat treatment on microstructure evolution and pitting corrosion behavior of UNS S31803 duplex stainless steel welds. Corrosion Science, 2012. 62: p. 42-50.

10. Mourad, A., A. Khourshid, and T. Sharef, Gas tungsten arc and laser beam welding processes effects on duplex stainless steel 2205 properties. Materials Science and Engineering: A, 2012. 549: p. 105-113.

11. Han, D., et al., Effect of temperature, chloride ion and $\mathrm{pH}$ on the crevice corrosion behavior of SAF 2205 duplex stainless steel in chloride solutions. Journal of materials science, 2012. 47(2): p. 1018-1025.

12. Omura, T., T. Kushida, and Y. Komizo, Nitrogen distribution on rapid solidification in laser welded duplex stainless steels. Welding International, 2000. 14(4): p. 288294.

13. Matsunaga, H., et al., Effect of nitrogen on corrosion of duplex stainless steel weld metal. Science and Technology of Welding and Joining, 1998. 3(5): p. 225-232.

14. Sato, Y.S. and H. Kokawa, Preferential precipitation site of sigma phase in duplex stainless steel weld metal. Scripta Materialia, 1999. 40(6): p. 659-663.

15. Sato, Y., et al., Microstructure and mechanical properties of friction stir welded SAF 2507 super duplex stainless steel. Materials Science and Engineering: A, 2005. 397(1): p. 376-384. 
16. Muthupandi, V., et al., Effect of weld metal chemistry and heat input on the structure and properties of duplex stainless steel welds. Materials Science and Engineering: A, 2003. 358(1): p. 9-16.

17. Vasantharaja, P., et al., Assessment of Residual Stresses and Distortion in Stainless Steel Weld Joints. Materials and Manufacturing Processes, 2012. 27(12): p. 13761381.

18. Li, Y., S. Hu, and J. Shen, The Effect of Peak Power and Pulse Duration for Dissimilar Welding of Brass to Stainless Steel. Materials and Manufacturing Processes, 2014(just-accepted).

19. Tathgir, S., A. Bhattacharya, and T.K. Bera, Influence of Current and Shielding Gas in TiO2 Flux Activated TIG Welding on Different Graded Steels. Materials and Manufacturing Processes, 2014(just-accepted).

20. Shi, H., et al., Effect of welding time on the joining phenomena of diffusion welded joint between aluminum alloy and stainless steel. Materials and Manufacturing Processes, 2012. 27(12): p. 1366-1369.

21. Li, C., et al., Effect of welding speed in high speed laser-TIG welding of magnesium alloy. Materials and Manufacturing Processes, 2012. 27(12): p. 1424-1428.

22. Narsimhachary, D., et al., Influence of Temperature Profile during Laser Welding of Aluminium Alloy 6061 T6 on Microstructure and Mechanical Properties. Materials and Manufacturing Processes, 2014(just-accepted).

23. He, X., Finite element analysis of laser welding: a state of art review. Materials and Manufacturing Processes, 2012. 27(12): p. 1354-1365.

24. Kwok, C., et al., Effect of laser surface melting on intergranular corrosion behaviour of aged austenitic and duplex stainless steels. Corrosion Science, 2011. 53(4): p. 1581-1591.

25. Lee, J.H., et al., Laser, tungsten inert gas, and metal active gas welding of DP780 steel: Comparison of hardness, tensile properties and fatigue resistance. Materials \& Design, 2014. 64: p. 559-565.

26. Magudeeswaran, G., et al., Optimization of process parameters of the activated tungsten inert gas welding for aspect ratio of UNS S32205 duplex stainless steel welds. Defence Technology, 2014. 10(3): p. 251-260.

27. Capello, E., et al., Laser welding and surface treatment of a 22Cr-5Ni-3Mo duplex stainless steel. Materials Science and Engineering: A, 2003. 351(1): p. 334-343.

28. Buddu, R., N. Chauhan, and P. Raole, Investigations of Microstructure and Mechanical Properties of 60-mm-Thick Type 316L Stainless Steel Welded Plates by Multipass Tungsten Inert Gas Welding and Electron Beam Welding for Fusion Reactor Applications. FUSION SCIENCE AND TECHNOLOGY, 2014. 65(2): p. 248-254.

29. Pekkarinen, J. and V. Kujanpää, The effects of laser welding parameters on the microstructure of ferritic and duplex stainless steels welds. Physics Procedia, 2010. 5: p. 517-523.

30. Ye, X., et al., Precipitates in Coarse-Grained Heat-Affected Zone of Ni-Based 718 Superalloy Produced by Tungsten Inert Gas Welding. Journal of Materials Processing Technology, 2014.

31. Hilkes, J. and K. Bekkers, Welding duplex stainless steel. Welding Journal (Miami, Fla), 1995. 74(11): p. 51-54.

32. Nilsson, J.O., Super duplex stainless steels. Materials Science and Technology, 1992. 8(8): p. 685-700. 
33. Mirakhorli, F., F.M. Ghaini, and M. Torkamany, Development of weld metal microstructures in pulsed laser welding of duplex stainless steel. Journal of materials engineering and performance, 2012. 21(10): p. 2173-2176.

34. Hertzman, S., P.J. Ferreira, and B. Brolund, An experimental and theoretical study of heat-affected zone austenite reformation in three duplex stainless steels. Metallurgical and Materials Transactions A: Physical Metallurgy and Materials Science, 1997. 28(2): p. 277-285.

35. Delobelle, V., et al., Resistance welding of NiTi shape memory alloy tubes. Journal of Materials Processing Technology, 2013. 213(7): p. 1139-1145.

36. Silva Dias, J., et al. Influence of Welding Parameters in Substrate/Coating of Galvanized Sheets Using Resistance Spot Welding. in Materials Science Forum. 2013. Trans Tech Publ.

37. Isayev, A. and A. Terekhov, Mechanical properties of resistance spot welded joints in zinc-plated TRIP steel. Welding International, 2014. 28(4): p. 324-328.

38. Kuroda, T., K. Ikeuchi, and H. Ikeda, Flash butt resistance welding for duplex stainless steels. Vacuum, 2006. 80(11): p. 1331-1335.

39. Kuroda, T. and M. Shimada, Micro flash butt welding of super duplex stainless steel with Zr-based metallic glass insert. Vacuum, 2008. 83(1): p. 153-156.

40. Folkhard, E. and G. Rabensteiner, Welding metallurgy of stainless steels. 1988: Springer.

41. Liao, J., N. Yamamoto, and K. Nakata, Gas tungsten arc welding of fine-grained AZ31B magnesium alloys made by powder metallurgy. Materials \& Design, 2014. 56: p. $460-467$.

42. Ganesh, K., et al., Thermo-Mechanical Analysis of TIG Welding of AISI 316LN Stainless Steel. Materials and Manufacturing Processes, 2014(just-accepted).

43. Morisada, Y., H. Fujii, and N. Xukun, Development of simplified active flux tungsten inert gas welding for deep penetration. Materials \& Design, 2014. 54: p. 526-530.

44. Tseng, K.-H., Development and application of oxide-based flux powder for tungsten inert gas welding of austenitic stainless steels. Powder technology, 2013. 233: p. 7279.

45. Korra, N.N., M. Vasudevan, and K. Balasubramanian, Multi-objective optimization of activated tungsten inert gas welding of duplex stainless steel using response surface methodology. The International Journal of Advanced Manufacturing Technology, 2014: p. 1-15.

46. Sathiya, P., et al., Effect of shielding gases on mechanical and metallurgical properties of duplex stainless-steel welds. Journal of materials science, 2009. 44(1): p. 114-121.

47. Zhu, Z., et al., Effect of post weld heat treatment on the microstructure and corrosion behavior of AA2219 aluminum alloy joints welded by variable polarity tungsten inert gas welding. Materials \& Design, 2014.

48. Taban, E., Joining of duplex stainless steel by plasma arc, TIG, and plasma Arc+ TIG welding processes. Materials and Manufacturing Processes, 2008. 23(8): p. 871-878.

49. Zhang, J., et al., The microstructure and impact toughness of simulated welding HAZ in 2205 duplex stainless steel. Xiyou Jinshu Cailiao yu Gongcheng(Rare Metal Materials and Engineering), 2006. 35(11): p. 1822-1825.

50. Korra, N.N., K. Balasubramanian, and M. Vasudevan, Optimization of activated tungsten inert gas welding of super duplex alloy 2507 based on experimental results. Proceedings of the Institution of Mechanical Engineers, Part B: Journal of Engineering Manufacture, 2014: p. 0954405414537245. 
51. Badji, R., et al., Phase transformation and mechanical behavior in annealed 2205 duplex stainless steel welds. Materials Characterization, 2008. 59(4): p. 447-453.

52. Van Nassau, L., H. Meelker, and J. Hilkes, Welding duplex and super-duplex stainless steels. Duplex Stainless Steels'91., 1991. 1: p. 303-323.

53. Urena, A., et al., Weldability of a 2205 duplex stainless steel using plasma arc welding. Journal of Materials Processing Technology, 2007. 182(1): p. 624-631.

54. Karlsson, L. and J. Tolling. Experiences and new possibilities in welding duplex stainless steels. in Proc. IIW Regional Congress on "Welding and related inspection technologies", Stellenbosch, South Africa. 2006.

55. Siegmund, T., E. Werner, and F.D. Fischer, Structure-property relations in duplex materials. Computational Materials Science, 1993. 1(3): p. 234-240.

56. Kokawa, H., M. Tomita, and T. Kuwana, Effect of nitrogen on impact toughness of duplex stainless steel weld metal. Welding International, 1995. 9(3): p. 217-224.

57. Chern, T.-S., K.-H. Tseng, and H.-L. Tsai, Study of the characteristics of duplex stainless steel activated tungsten inert gas welds. Materials \& Design, 2011. 32(1): p. 255-263.

58. Liu, L. and H. Sun, Study of flux assisted TIG welding of magnesium alloy with SiC particles in flux. Materials Research Innovations, 2008. 12(1): p. 47-51.

59. Marya, M. and G. Edwards, Chloride contributions in flux-assisted GTA welding of magnesium alloys. WELDING JOURNAL-NEW YORK-, 2002. 81(12): p. 291-S.

60. Southwick, P. and R. Honeycombe, Decomposition of ferrite to austenite in $26 \% \mathrm{Cr}$ 5\% Ni stainless steel. Metal Science, 1980. 14(7): p. 253-261.

61. Eghlimi, A., M. Shamanian, and K. Raeissi, Effect of current type on microstructure and corrosion resistance of super duplex stainless steel claddings produced by the gas tungsten arc welding process. Surface and Coatings Technology, 2014. 244: p. 45-51.

62. Yousefieh, M., M. Shamanian, and A. Saatchi, Optimization of the pulsed current gas tungsten arc welding (PCGTAW) parameters for corrosion resistance of super duplex stainless steel (UNS S32760) welds using the Taguchi method. Journal of Alloys and Compounds, 2011. 509(3): p. 782-788.

63. Wang, H.S., Effect of welding variables on cooling rate and pitting corrosion resistance in super duplex stainless weldments. Materials Transactions, 2005. 46(3): p. 593-601.

64. Ramirez, A.J., J.C. Lippold, and S.D. Brandi, The relationship between chromium nitride and secondary austenite precipitation in duplex stainless steels. Metallurgical and Materials Transactions A: Physical Metallurgy and Materials Science, 2003. 34 A(8): p. 1575-1597.

65. Ramirez, A.J., S.D. Brandi, and J.C. Lippold, Secondary austenite and chromium nitride precipitation in simulated heat affected zones of duplex stainless steels. Science and Technology of Welding and Joining, 2004. 9(4): p. 301-313.

66. Liou, H.Y., R.I. Hsieh, and W.T. Tsai, Microstructure and stress corrosion cracking in simulated heat-affected zones of duplex stainless steels. Corrosion Science, 2002. 44(12): p. 2841-2856.

67. Yang, Y., et al., The effect of large heat input on the microstructure and corrosion behaviour of simulated heat affected zone in 2205 duplex stainless steel. Corrosion Science, 2011. 53(11): p. 3756-3763.

68. Nowacki, J. and A. Łukojć, Structure and properties of the heat-affected zone of duplex steels welded joints. Journal of Materials Processing Technology, 2005. 164165: p. 1074-1081.

69. Palmer, T.A., J.W. Elmer, and S.S. Babu, Observations of ferrite/austenite transformations in the heat affected zone of 2205 dupex stainless steel spot welds 
using time resolved X-ray diffraction. Materials Science and Engineering A, 2004. 374(1-2): p. 307-321.

70. Perren, R.A., et al., Corrosion resistance of super duplex stainless steels in chloride ion containing environments: Investigations by means of a new microelectrochemical method. II. Influence of precipitates. Corrosion Science, 2001. 43(4): p. 727-745.

71. Garzón, C.M. and A.J. Ramirez, Growth kinetics of secondary austenite in the welding microstructure of a UNS S32304 duplex stainless steel. Acta Materialia, 2006. 54(12): p. 3321-3331.

72. Wang, S.-H., et al., Gamma $(\gamma)$ phase transformation in pulsed GTAW weld metal of duplex stainless steel. Materials Science and Engineering: A, 2006. 420(1): p. 26-33.

73. kumar, K.S., S. Gejendhiran, and M. Prasath, Comparative Investigation of Mechanical Properties in GMAW/GTAW for Various Shielding Gas Compositions. Materials and Manufacturing Processes, 2014(just-accepted).

74. Hashemi, R., H. Pashazadeh, and M. Hamedi, An incrementally coupled thermoelectro-mechanical model for resistance spot welding. Materials and Manufacturing Processes, 2012. 27(12): p. 1442-1449.

75. Lin, H.-L. and C.-P. Chou, Optimization of the GTA welding process using combination of the Taguchi method and a neural-genetic approach. Materials and Manufacturing Processes, 2010. 25(7): p. 631-636.

76. Tanabe, H., et al., Modeling of the deoxidization process on submerged arc weld metals. Welding in the World, 2014. 58(1): p. 41-45.

77. Rao, R.V. and V. Kalyankar, Experimental investigation on submerged arc welding of $\mathrm{Cr}-\mathrm{Mo}-\mathrm{V}$ steel. The International Journal of Advanced Manufacturing Technology, 2013. 69(1-4): p. 93-106.

78. Annoni, R., et al., Submerged-arc welding slags: Characterization and leaching strategies for the removal of aluminum and titanium. Journal of hazardous materials, 2013. 244: p. 335-341.

79. Cater, S., et al., Comparison between friction stir and submerged arc welding applied to joining DH36 and E36 shipbuilding steel. Friction Stir Welding and Processing VII, 2013: p. 47-58.

80. Cho, D.-W., et al., Analysis of submerged arc welding process by three-dimensional computational fluid dynamics simulations. Journal of Materials Processing Technology, 2013. 213(12): p. 2278-2291.

81. Young, M.C., et al., Hydrogen-enhanced cracking of 2205 duplex stainless steel welds. Materials Chemistry and Physics, 2005. 91(1): p. 21-27.

82. Luo, J., et al., Microstructure of 2205 duplex stainless steel joint in submerged arc welding by post weld heat treatment. Journal of Manufacturing Processes, 2013.

83. Luo, J., et al., Double-Sided Single-Pass Submerged Arc Welding for 2205 Duplex Stainless Steel. Journal of materials engineering and performance, 2013. 22(9): p. 2477-2486.

84. McPherson, N., K. Chi, and T. Baker, Submerged arc welding of stainless steel and the challenge from the laser welding process. Journal of Materials Processing Technology, 2003. 134(2): p. 174-179.

85. Saeid, T., et al., Effect of friction stir welding speed on the microstructure and mechanical properties of a duplex stainless steel. Materials Science and Engineering: A, 2008. 496(1): p. 262-268.

86. Sato, Y.S., et al., Microstructural evolution of ultrahigh carbon steel during friction stir welding. Scripta Materialia, 2007. 57(6): p. 557-560.

87. Lienert, T., et al., Friction stir welding studies on mild steel. WELDING JOURNALNEW YORK-, 2003. 82(1): p. 1-S. 
88. Reynolds, A., et al., Friction stir welding of DH36 steel. Science and Technology of Welding \& Joining, 2003. 8(6): p. 455-460.

89. Park, S.H.C., et al., Rapid formation of the sigma phase in 304 stainless steel during friction stir welding. Scripta Materialia, 2003. 49(12): p. 1175-1180.

90. Kim, Y., et al., Three defect types in friction stir welding of aluminum die casting alloy. Materials Science and Engineering: A, 2006. 415(1): p. 250-254.

91. Chen, H.-B., et al., The investigation of typical welding defects for 5456 aluminum alloy friction stir welds. Materials Science and Engineering: A, 2006. 433(1): p. 6469.

92. Schneider, J. and A. Nunes Jr, Characterization of plastic flow and resulting microtextures in a friction stir weld. Metallurgical and materials transactions B, 2004. 35(4): p. 777-783.

93. Maki, T., T. Furuhara, and K. Tsuzaki, Microstructure development by thermomechanical processing in duplex stainless steel. ISIJ International, 2001. 41(6): p. 571-579.

94. Lippold, J.C. and D.J. Kotecki, Welding metallurgy and weldability of stainless steels. Welding Metallurgy and Weldability of Stainless Steels, by John C. Lippold, Damian J. Kotecki, pp. 376. ISBN 0-471-47379-0. Wiley-VCH, March 2005., 2005. 1.

95. Martikainen, J., Conditions for achieving high-quality welds in the plasma-arc keyhole welding of structural steels. Journal of Materials Processing Tech., 1995. 52(1): p. 68-75.

96. Craig, E., PLASMA ARC PROCESS - A REVIEW. Welding Journal (Miami, Fla), 1988. 67(2): p. 19-25.

97. Wang, Y. and Q. Chen, On-line quality monitoring in plasma-arc welding. Journal of Materials Processing Technology, 2002. 120(1-3): p. 270-274.

98. Kumar, S. and A.S. Shahi, On the Influence of Welding Stainless Steel on Microstructural Development and Mechanical Performance. Materials and Manufacturing Processes, 2013(just-accepted).

99. Gooch, T.G., Welding new stainless steels for the oil and gas industry. Stainless steel world, 2000. 12(5): p. 48-59.

100. Petronius, I. and M. Bamberger, Microstructure and properties following welding of duplex stainless steel using coated electrodes. Science and Technology of Welding \& Joining, 2001. 6(2): p. 79-83.

101. Sun, Z., et al., Effect of dual torch technique on duplex stainless steel welds. Materials Science and Engineering: A, 2003. 356(1): p. 274-282. 